\title{
Iglesias, rentas y sistemas de almacenamiento en el País Vasco durante los siglos x y XI d. C.: el testimonio arqueológico de San Martín de Dulantzi (Alegría-Dulantzi, Álava)
}

\section{Churches, rents and storage systems in the Basque Country during the $10^{\text {th }}$ and $11^{\text {th }}$ centuries AD: the archeological heritage of San Martín de Dulantzi (Alegría-Dulantzi, Álava)}

\author{
Egoitz Alfaro Suescun ${ }^{1}$ \\ Universidad del País Vasco UPV/EHU \\ Miguel Loza Uriarte ${ }^{2}$ \\ Javier Niso Lorenzo ${ }^{3}$ \\ Iterbide S.C. Arqueología y Patrimonio \\ Jose Luis Solaun Bustinza ${ }^{4}$ \\ Universidad del País Vasco UPV/EHU
}

\section{RESUMEN}

En el presente artículo se analizan los más de 30 silos abiertos durante los siglos x y XI en el interior de la basílica altomedieval de Dulantzi (Alegría-Dulantzi, Álava). El texto pretende alcanzar un doble objetivo. Por un lado, presentar a la comunidad científica este importante conjunto de silos del que hasta el momento sólo se había dado noticia escuetamente. Para ello, se aportarán todos los datos arqueológicos que ha proporcionado el estudio, tanto de los continentes (capacidad, morfología, situación, etc.), como de los contenidos (tipos de rellenos y material localizado en ellos). Por otro, continuar con el debate historiográfico sobre la presencia de silos en iglesias altomedievales. En este sentido, estructuraremos nuestras reflexiones en torno a tres ejes: las razones que explican el elevado número de silos abiertos en Dulantzi; su posible relación con la captación y almacenamiento de rentas eclesiásticas; y, finalmente, su excepcionalidad: ¿fue Dulantzi un caso singular o, por el contrario, su modelo explicativo puede ser extrapolado a otros yacimientos altomedievales del entorno?

\section{SUMMARY}

This paper will look at the thirty plus open storage pits located at the high middle age basilica of Dulantzi (AlegríaDulantzi, Álava) dating back to the tenth and eleventh centuries

\footnotetext{
legoitz.alfaro@gmail.com / ORCID iD: http://orcid org/0000-0002-7617-0490

2 iterbide@yahoo.es / ORCID iD: http://orcid.org/0000-00020223-5810

3 iterbide@yahoo.es / ORCID iD: http://orcid.org/0000-00032965-7498

4 joseluis.solaun@ehu.eus / ORCID iD: http:// orcid. org/0000-0001-8441-3213
}

In the first instance we propose to present this little-known site to the scientific community. To do so, different archaeological data gathered during the excavation will be presented involving both the containers (capacity, morphology, location, etc.) as the contents (types of fillings and material found in them). The second aim of this paper is to contribute towards the historical debate about the presence of storage pits in high middle age churches. To do so, our contribution will follow three different axis. First, the reasons that explain the high number of opened storage pits in Dulantzi. Secondly, its possible connections to the collection and storage of ecclesiastical rents. The final question to be looked relates to whether Dulantzi was an exception or on the contrary, is an explanatory model from which we can extrapolate concerning other high middle age sites in the surrounding area.

PALABRAS CLAVE: Alta Edad Media; iglesias; silos; contexto arqueológico; poderes laicos y eclesiásticos.

KEY WORDS: Early Middle Ages; churches; Storage Pits silos; archaeological context; secular and ecclesiastical powers.

CÓMO CITAR ESTE ARTÍCULO / CITATION: Alfaro Suescun, E., Loza Uriarte, M., Niso Lorenzo, J. y Solaun Bustinza, J. L.. 2017: "Iglesias, rentas y sistemas de almacenamiento en el País Vasco durante los siglos x y XI d. C.: el testimonio arqueológico de San Martín de Dulantzi (Alegría-Dulantzi, Álava)". Archivo Español de Arqueología, 90: 247-270. doi: 10.3989/aespa.090.017.011

\section{INTRODUCCIÓN}

El congreso internacional sobre "Horrea, Barns and silos. Storages and incomes in Early Medieval 
Europe" celebrado en Vitoria-Gasteiz en el año 2011 supuso un antes y un después a la hora de "comprender la complejidad de las relaciones sociales que se establecen en torno a los procesos de gestión de las cosechas, su almacenaje a corto y largo plazo, los sistemas de captación de rentas y, en general, las formas de articulación de la arqueología agraria de las sociedades altomedievales" (Quirós 2013: 11).

Las actas de este congreso posibilitaron, en efecto, un conocimiento actualizado de los últimos estudios realizados a nivel europeo sobre las estructuras de almacenaje existentes en la Alta Edad Media. Se trató, además, de un trabajo en el que coexistieron aportaciones, tanto de la documentación textual y etnoarqueología, como fundamentalmente de la arqueología, y que, por lo tanto, permitía obtener una visión multidisciplinar de esta cuestión. De este modo, se profundizaba en aspectos taxonómicos, resolviendo cuestiones formales como qué es un silo, qué tipologías y capacidades presentan, etc.; e interpretativos, recalcando la importancia que tenían estas estructuras de almacenaje, en muchos casos únicos testimonios conservados para entender el comportamiento de las sociedades altomedievales. Finalmente, gracias al análisis comparativo de la distinta casuística estudiada, se pudo establecer una serie de pautas de comportamientos generales.

Una de ellas fue la presencia de silos en las iglesias altomedievales, fenómeno estudiado por muchos de los autores que participaron en dicho congreso. Entre ellos, destacaremos a J. Roig, por ser Cataluña el lugar donde más extensamente se ha investigado el tema (y consecuentemente donde mejor se conoce), y J. A. Quirós, por haber tratado la problemática en nuestro territorio. Ambos autores abordan detenidamente esta cuestión, analizándola desde la perspectiva social y funcional.

De forma general, J. Roig relaciona la presencia de estos silos con el almacenaje del excedente agrícola que genera el alodio de la iglesia a lo largo del siglo $\mathrm{X}$, así como con el diezmo eclesiástico (Roig 2013: 168-169); J. A. Quirós, por su parte, considera que, hasta esa fecha, la casuística documentada en el País Vasco no permite establecer aseveraciones generales sobre su interpretación (Quirós 2013: 186). Aun así, este investigador recoge alguna de las hipótesis que habían sido planteadas hasta el momento para explicar los casos documentados en nuestro territorio. Podemos destacar dos de ellas.

Por un lado, la que ofrecen I. García Camino y M. Neira para el silo hallado en el interior del templo de Santa Lucia de Gerrika, en Bizkaia, datado entre los siglos IX y X. Estos autores, siguiendo a grandes rasgos las propuestas para territorio castellano de F.
Reyes (Reyes 1991: 89-90) o para Cataluña de V. Farías (2007), interpretan esta estructura como un lugar de almacenaje de los excedentes generados por las comunidades campesinas, como forma para escapar a la presión señorial (García Camino y Neira 2007: 370). Por otro, la que el mismo J. A. Quirós formula para explicar el elevado número de silos presentes en el interior de la basílica de San Martín de Dulantzi. Este autor propone que el templo (y con él los silos) estuvo durante los siglos IX y $\mathrm{x}$ en manos de elites locales que disponían de una importante capacidad de almacenaje y, por ende, de captación de rentas (Quirós 2013: 184).

Este breve análisis al estado de la cuestión peninsular de dicho fenómeno no hace sino resaltar la importancia del caso de San Martín de Dulantzi. De hecho, y aunque tenemos en cuenta que cada territorio tiene una problemática propia que responde tanto a su propia realidad histórica como al mayor o menor desarrollo de la investigación, sorprende el reducido número de silos presentes en el interior de las iglesias estudiadas (tanto en Cataluña, como en el País Vasco), en relación con los encontrados en Dulantzi.

Hay que tener en cuenta que, gracias a una nueva intervención arqueológica efectuada en este yacimiento en el verano de 2014 (Loza y Niso 2015), el número total de silos interiores ha sido ampliado a 35 , el doble de los que se conocían en el momento de celebrar el congreso internacional. Ello indudablemente incrementa las capacidades hermenéuticas del yacimiento. Por esa razón, y dado que han pasado varios años desde que se plantearan las primeras hipótesis sobre los silos presentes en el interior del templo de Dulantzi, hemos considerado oportuno elaborar un trabajo que, aportando nuevos datos, aborde de forma monográfica estas problemáticas ${ }^{5}$.

\section{EL YACIMIENTO DE SAN MARTÍN DE DU- LANTZI}

El yacimiento de San Martín de Dulantzi se localiza al norte de la actual villa de Alegría-Dulantzi (Álava), a escasos $15 \mathrm{~km}$ de Vitoria-Gasteiz (Fig. 1). La villa de Alegría fue fundada por iniciativa de Alfonso XI en el año 1337 sobre la aldea de Dulantzi, documentada desde el siglo XI y situada en proximidad de la sede de Tullonium, una de las ciudades de

\footnotetext{
${ }^{5}$ Buena parte del capítulo interpretativo del presente texto ha sido realizado a partir de las ideas desarrolladas en la tesis doctoral defendida por E. Alfaro en enero de 2016. Dicho trabajo, titulado La formación de la red parroquial en Álava y Treviño. Evidencias desde la arqueología (siglos XI-XIII), se encuentra actualmente inédito.
} 


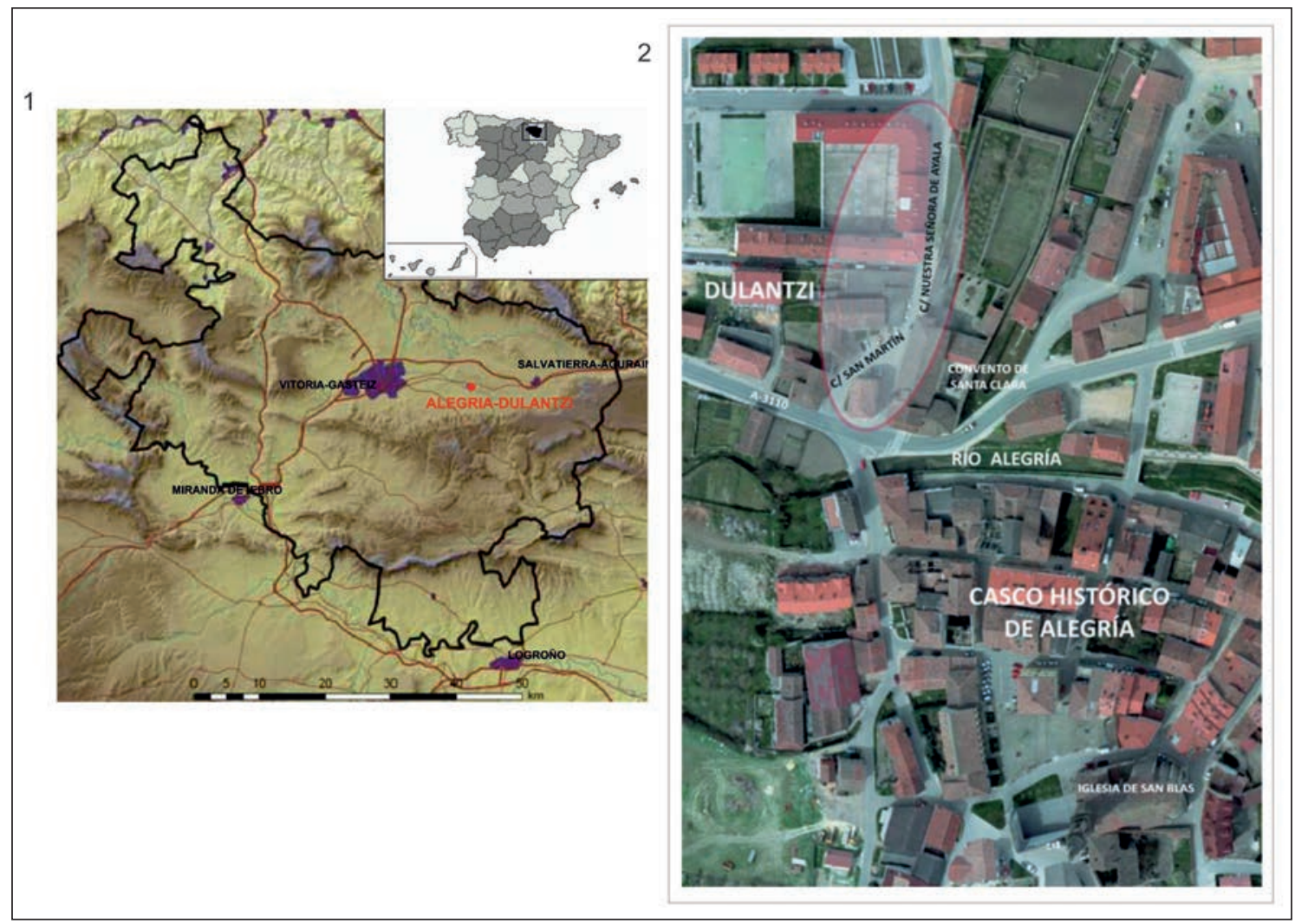

Figura 1. 1. Emplazamiento de la villa de Alegría-Dulantzi (Álava). 2. Ortofoto de la zona intervenida.

los várdulos mencionada por Ptolomeo y nuevamente citada en el Itinerario Antonino (Gurruchaga 1951: 222-231).

\subsection{SECUENCIA GENERAL DEL YACIMIENTO}

Hasta el momento dos han sido las actuaciones arqueológicas realizadas en este yacimiento, que cuenta con un total de $800 \mathrm{~m}^{2}$ de superficie intervenida y una amplía secuencia histórica documentada desde la protohistoria hasta la actualidad. Esta secuencia, desarrollada en varios trabajos anteriores (Loza y Niso 2012 y 2015), se puede resumir en ocho fases:

FASE 1. Siglo II $a$. C. Varias estructuras excavadas en el estrato geológico a modo de posibles fondos de cabaña de planta irregular y de grandes dimensiones pertenecientes a una ocupación de la Edad del Hierro.

FASE 2. Siglos I al IV d. C. En época altoimperial se detectan dos momentos de ocupación. Un primer poblamiento basado en estructuras perecederas con pavimento a nivel de suelo y semiexcavado. Otro posterior que parece circunscribirse a los últimos años del siglo I d. C. o ya a la siguiente centuria, con estructuras murarias pétreas en torno a una calle. A partir del siglo III se produjo una importante reestructuración en el asentamiento de la que apenas se han conservado restos constructivos.

FASE 3. Siglo vd. C. - $1^{a}$ mitad siglo vi d. C. Salvo quizá una primera ocupación de carácter funerario, hay una llamativa ausencia de evidencias arqueológicas del siglo v. Por el contrario, durante la primera mitad del siglo vi se observa una densificación de los testimonios arqueológicos, basados nuevamente en estructuras perecederas.

FASE 4. $2^{a}$ mitad siglo VI d. C. - Siglo VII d. C. En los años centrales del siglo vi se levantó un gran edificio de culto asociado a una necrópolis interior formada por enterramientos privilegiados con ricos ajuares y depósitos funerarios. Al exterior del mismo continuaron existiendo numerosas estructuras con pavimento semiexcavado.

FASE 5. Finales siglo VII d. C.- $2^{a}$ mitad siglo IX $d$. C. Se mantiene en uso el edificio eclesiástico, pero se amortiza la necrópolis de prestigio, que fue sustituida por un cementerio comunitario situado al exterior del templo y que parece convivir con algunas estructuras domésticas. 
FASE 6. $1^{a}$ mitad siglo $\mathrm{x}$ d. C. - Principios siglo XII $d$. C. Continuidad del templo y del cementerio comunitario, que en este momento alcanzó su mayor extensión, manteniéndose también diversas estructuras domésticas. Lo más destacable, sin embargo, es la presencia en su interior de un gran número de silos de almacenaje que se fueron abriendo y amortizando de forma diacrónica, hasta su total abandono a finales del siglo XI o principios del siglo XII.

FASE 7. Siglos XII-XIV d. C. En la primera mitad del siglo XII tuvo lugar el abandono del gran edificio de culto y, unas décadas más tarde, se erigió la iglesia de San Martín, acompañada de un nuevo cementerio. Atendiendo a la documentación escrita, parece que la función parroquial de esta iglesia pervivió más allá de la fundación de la villa de Alegría en 1337, probablemente hasta el siglo XV (Portilla 1978: 249-259).

FASE 8. Siglos XV al XXI. Transformaciones posteriores asociadas al urbanismo de la villa.

\subsection{Los SIGLOS VI AL XII D. C.}

Serán los siglos VI-XII (fases 3-6) los que se tomarán en consideración en este trabajo, por ser aquellos en los que se han detectado silos. El punto de partida es la construcción, en los años centrales del siglo VI, de un gran edificio eclesiástico que modificó totalmente el hábitat preexistente, convirtiéndose durante casi 700 años en el foco vertebrador de todo el lugar. A pesar de no haberse podido excavar en su totalidad y de que lo encontrado se encuentra notablemente alterado por actividades posteriores, ha sido posible reproducir su planta basilical de $315 \mathrm{~m}^{2}$ de superficie ${ }^{6}$, perfectamente orientada este-oeste.

Al este se ha documentado su cabecera, seguramente tripartita. De la misma se conserva la sala central, identificada con el sanctuarium, y la cámara sureste, de funcionalidad funeraria constatada, que también pudo hacer las veces de sacrarium ${ }^{7}$. La parte central del complejo estaría ocupada por el aula, dividida en tres naves, cuya parte más cercana al sanctuarium pudo haber servido también de acceso restringido al clero, a modo de chorus $^{8}$. El aula tam-

\footnotetext{
${ }^{6}$ Se trata de una estimación mínima teniendo en cuenta los restos de la iglesia que se han documentado, ya que todavía falta por descubrir la zona de los pies y el cierre de la nave septentrional. Además, hay que tener en cuenta que algunas partes del edificio ya están perdidas irremediablemente como consecuencia de construcciones modernas.

${ }^{7}$ Por su parte, la cámara noreste se encontraría bajo una vivienda actual.

${ }^{8}$ La presencia de un posible espacio restringido en el aula es una propuesta que todavía sólo alcanza el grado de hipótesis y que se sustenta en la no aparición de enterramientos en esa
}

bién tendría un uso funerario en toda su superficie, a excepción del anteriormente mencionado coro. Por último, al sur de esta gran sala central y aparentemente de forma exenta, se ha identificado el baptisterium, con una piscina de inmersión central. La zona de los pies no ha podido ser registrada, por lo que no es posible determinar cómo cerraba el edificio.

En sus primeros años de vida, la basílica fue utilizada como lugar privilegiado de enterramiento. Hasta el momento, se han documentado 30 inhumaciones datadas entre la segunda mitad del siglo VI y el siglo viI: 20 en el aula, 3 en el sacrarium y 7 al exterior de la basílica, en un espacio también de privilegio y quizás delimitado para ello, sin que se hayan detectado en el sanctuarium y el baptisterum, posiblemente por su mayor componente litúrgico. Estos enterramientos estaban inhumados de forma ordenada en fosas, simples o colectivas, con los individuos generalmente descansando en ataúdes de madera armados con clavos. Además, muchos de ellos estaban acompañados en su ritual funerario por distintos objetos de prestigio, algunos de ellos de clara influencia norpirenaica.

$\mathrm{Al}$ exterior se detectaron, asimismo, diversas estructuras excavadas de aparente carácter doméstico: agujeros de postes, rozas, fondos rehundidos de cabaña y silos. La basílica anuló algunas de ellas, mientras que otras funcionaron con ella hasta su amortización, en muchos casos motivada por la ubicación a partir del siglo viII de un nuevo cementerio exterior. Este nuevo espacio funerario coincide con el abandono de la necrópolis de prestigio interior. Se trata de un cementerio muy denso y longevo que se extiende por gran parte del yacimiento, conviviendo con un buen número de estructuras domésticas, entre ellas varios silos abiertos en los siglos X-XI ${ }^{9}$.

El interior de la basílica conoció en el siglo x una nueva e importante transformación, con la apertura de un gran número de silos de almacenamiento subterráneo que se fueron excavando y amortizando de forma diacrónica hasta finales del siglo XI o principios del siglo XII, fecha que coincide con la ruina y desmante-

área, en la presencia del arranque de una estructura muraria adosada a la primera pilastra de separación de las naves y en el hecho de que el acceso al sanctuarium debió estar abierto.

${ }^{9}$ Puede sorprender la ausencia de silos durante la fase 5 (finales del siglo vII d. C.- segunda mitad del siglo IX d. C.), sobre todo porque en este momento se detectan un gran número de estructuras domésticas al exterior del edificio eclesiástico. En nuestra opinión, las características particulares de la intervención arqueológica, que no permitieron la excavación en extensión de todo el yacimiento, pueden ser las razones que expliquen esta ausencia. Otra cuestión diferente es que no hayan sido identificadas en el interior del edificio eclesiástico, circunstancia que sí responde a un fenómeno particular del uso de la basílica en este periodo. 


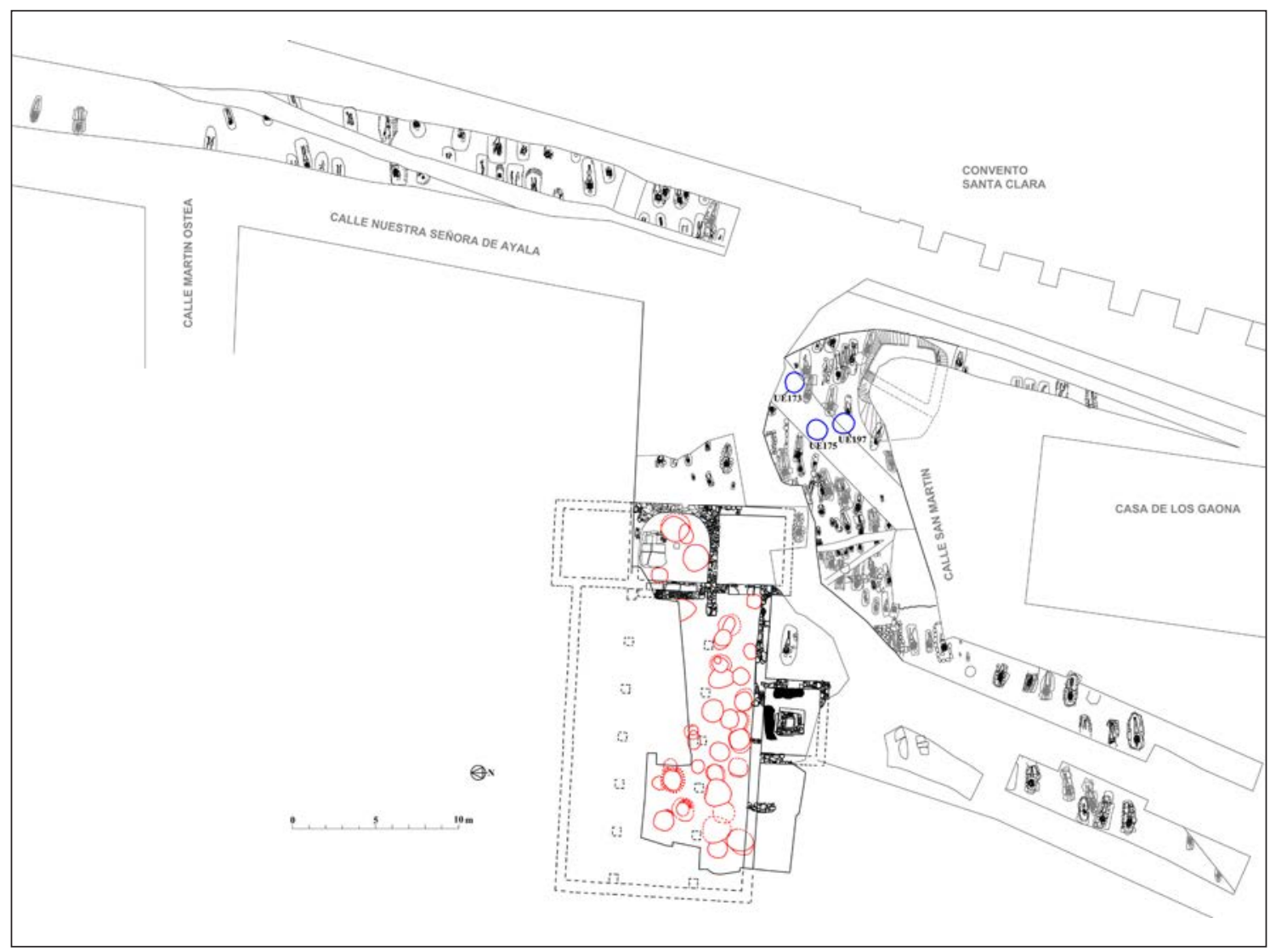

Figura 2. Planta de la basílica de San Martín, con su necrópolis exterior (siglos VIII-XI) y distintas estructuras domésticas coetáneas a ésta. Se destacan los silos documentados al interior y al exterior del edificio de culto.

lamiento definitivo del edificio de culto (Loza y Niso 2016). La presencia de estos silos, siempre ubicados en su interior, es el objeto de estudio de este trabajo.

\section{ANÁLISIS DEL CONJUNTO DE SILOS DOCU- MENTADO}

En las páginas anteriores se ha realizado un breve resumen de la secuencia general del yacimiento, ampliando la información de aquellas fases que más interesaba destacar para contextualizar debidamente el trabajo. Corresponde ahora analizar los silos que, como se ha visto, se agrupan en dos momentos cronológicos. El primero de ellos se data en los siglos vi y VII d. C. En esta etapa ya existía un hábitat integrado por distintas estructuras rupestres, entre las que se englobaban varios silos de almacenaje pertenecientes a la comunidad que habitaba Dulantzi, con anterioridad a la erección del edificio religioso. Estos silos responden, en consecuencia, a una casuística diferente a la planteada en este trabajo, por lo que únicamente nos centraremos en el análisis de las estructuras de almacenamiento pertenecientes a la segunda etapa, asociadas a la basílica de San Martín y fechadas entre los siglos x y XI.

Su estudio lo dividiremos en dos apartados. Uno primero referido al continente, es decir a la propia estructura arqueológica; y otro segundo relativo al contenido o, lo que es lo mismo, al material arqueológico recuperado en su interior (principalmente cerámico), puesto que, como veremos más adelante, permite ser utilizado como herramienta taxonómica (indicador cronológico) y hermenéutica (principalmente para comprender los procesos formativos en arqueología).

\subsection{LOS SILOS COMO ESTRUCTURA ARQUEOLÓGICA}

Atendiendo a la situación de los silos respecto a la iglesia se pueden diferenciar dos conjuntos. Por un lado, los 35 silos localizados en su interior. Por otro, tres silos localizados al exterior, concretamente a unos ocho metros al sureste de su cabecera y en 


\begin{tabular}{|c|c|c|c|c|c|c|c|c|}
\hline UE & Relleno por & $\begin{array}{c}\text { Diámetro sup. } \\
\text { conservado }\end{array}$ & $\begin{array}{c}\text { Diámetro inf. } \\
\text { conservado }\end{array}$ & $\begin{array}{c}\text { Diámetro máx. } \\
\text { conservado }\end{array}$ & $\begin{array}{c}\text { Altura } \\
\text { cons./estim. }\end{array}$ & $\begin{array}{c}\text { Volumen } \\
\text { cons. (L) }\end{array}$ & $\begin{array}{c}\text { Volumen } \\
\text { estim. (L) }\end{array}$ & Ubicación \\
\hline 173 & 172 & $120 \mathrm{~cm}$ & $110 \mathrm{~cm}$ & $120 \mathrm{~cm}$ & $114 / 120 \mathrm{~cm}$ & Muy alterado & c.a.1.000 & Ext. iglesia \\
\hline 175 & 174 & $120 \mathrm{~cm}$ & $110 \mathrm{~cm}$ & $120 \mathrm{~cm}$ & $62 / 120 \mathrm{~cm}$ & Muy alterado & c.a. 1.000 & Ext. iglesia \\
\hline 197 & 196 & $117 \mathrm{~cm}$ & $108 \mathrm{~cm}$ & $130 \mathrm{~cm}$ & $102 / 120 \mathrm{~cm}$ & Muy alterado & c.a.1.000 & Ext. iglesia \\
\hline
\end{tabular}

Figura 3. Dimensiones y capacidades de los silos localizados al exterior de la basílica.

el mismo espacio en que se sitúa el cementerio comunitario (Fig. 2).

\subsection{Silos AL EXTERIOR DE LA BASÍliCA}

Se trata de tres silos coetáneos a los registrados al interior del edificio. Sólo conservan su mitad mediainferior, al estar muy afectados por distintos arrasamientos, presentando unas dimensiones en torno a 1,2 $\mathrm{m}$ de diámetro conservado y una capacidad estimada de 1.000 litros (Fig. 3). Comparten las mismas relaciones estratigráficas, ya que cortan a enterramientos de la fase más antigua de la necrópolis comunitaria (finales del siglo vII d. C.- segunda mitad del siglo IX d. C.) y están cortados por sepulturas de la fase más moderna de esta misma necrópolis, cuyo uso final se sitúa a principios del siglo XII d. C.

\subsection{Silos AL inTERIOR DE LA BASÍLiCA}

Al interior de la basílica de San Martín se registraron un total de $35 \operatorname{silos}^{10}$. Su cronología, situada entre el siglo x y los primeros años del siglo XII, ha sido establecida principalmente a partir del material cerámico aparecido en sus rellenos de amortización, ya que las relaciones estratigráficas no permitían acotar una horquilla cronológica lo suficientemente válida. Más adelante profundizaremos en su cronología, abordando los problemas a los que nos hemos tenido que enfrentar para determinar el momento de su apertura y del posterior proceso de abandono. Ahora nos centraremos en las cuestiones relativas a su morfología y localización.

Localización. Los silos se sitúan en todo el espacio disponible de la iglesia, horadando la mayor parte del suelo de la nave y del ábside (Fig. 4). Tan sólo se respetan los elementos funcionales (columnas de separación de las naves, escalón de acceso al ábside) y litúrgicos/funerarios (tenante de altar, tumba privi-

\footnotetext{
${ }^{10}$ Se ha estimado que pudieron existir un total de 70 silos al interior del edificio religioso, el doble de los ahora documentados. Esta estimación se ha realizado teniendo en cuenta que se ha intervenido en aproximadamente la mitad de la superficie de la basílica.
}

legiada, sarcófago ${ }^{11}$ ). La magnitud de esta empresa queda patente en la apertura de silos cortando los rellenos de amortización de otros ya abandonados. De hecho, y a pesar de lo inconveniente que era abrir silos en un terreno poco consistente, se han documentado conjuntos de hasta cuatro estructuras cortadas entre si $^{12}$. Todo ello no hace sino recalcar el interés en situar los silos en el interior del edificio de culto, a pesar de los impedimentos que ello conllevaba.

Tipología. La importante afección de la estratigrafía más reciente, principalmente los enterramientos asociados a la iglesia levantada en el siglo XII, motivaron que gran parte de los silos no conservaran sus embocaduras y, por consiguiente, tampoco su morfología original. Por ello, pensamos que resulta más sensato no establecer aseveraciones de carácter genérico sobre sus perfiles y secciones, más allá de confirmar que sus bases eran generalmente planas o hemiesféricas (Figs. 4, 5 y 6). Otra cuestión diferente, aunque no menos problemática, es definir el sistema con el que se sellaban y permitían su convivencia con las funciones litúrgicas del edificio religioso. A este respecto, como indicaremos en el posterior epígrafe de los silos y sus rellenos, pensamos en la existencia de un entarimado de madera que permitiese esa coexistencia, previa cobertura de sus embocaduras. En este sentido, los rellenos de amortización de algunos silos han proporcionado elementos pétreos compatibles con su uso como tapadera.

Dimensiones. Como cabe deducir de los expresado anteriormente, las dimensiones originales de los silos también se han perdido. Aun así, conocemos la cota de suelo desde la que se excavaron, por lo que se ha

\footnotetext{
${ }^{11}$ Es posible que el respeto existente a algunos de estos restos no siempre fuera debido a razones cultuales, sino a las dificultades de abrir un silo en aquellos puntos del edificio donde se localizaban estructuras pétreas importantes, tales como un sarcófago o una tumba privilegiada. Esta hipótesis se sustenta en la falta de consideración alguna hacia los enterramientos vestidos de los siglos VI-VII, inhumados dentro de la gran aula, a los que cortan totalmente.

${ }^{12}$ La apertura de silos cortándose entre sí es un fenómeno poco frecuente en otros contextos, pero mayoritario en $\mathrm{Du}$ lantzi. Aunque este hecho pudo deberse a varias razones, la principal fue probablemente su mala conservación, resultado de abrirlos en un terreno blando y poco consistente. Ello podemos suponer atendiendo al mal estado en el que se encontraban sus paredes, en muchos casos caídas,
} 


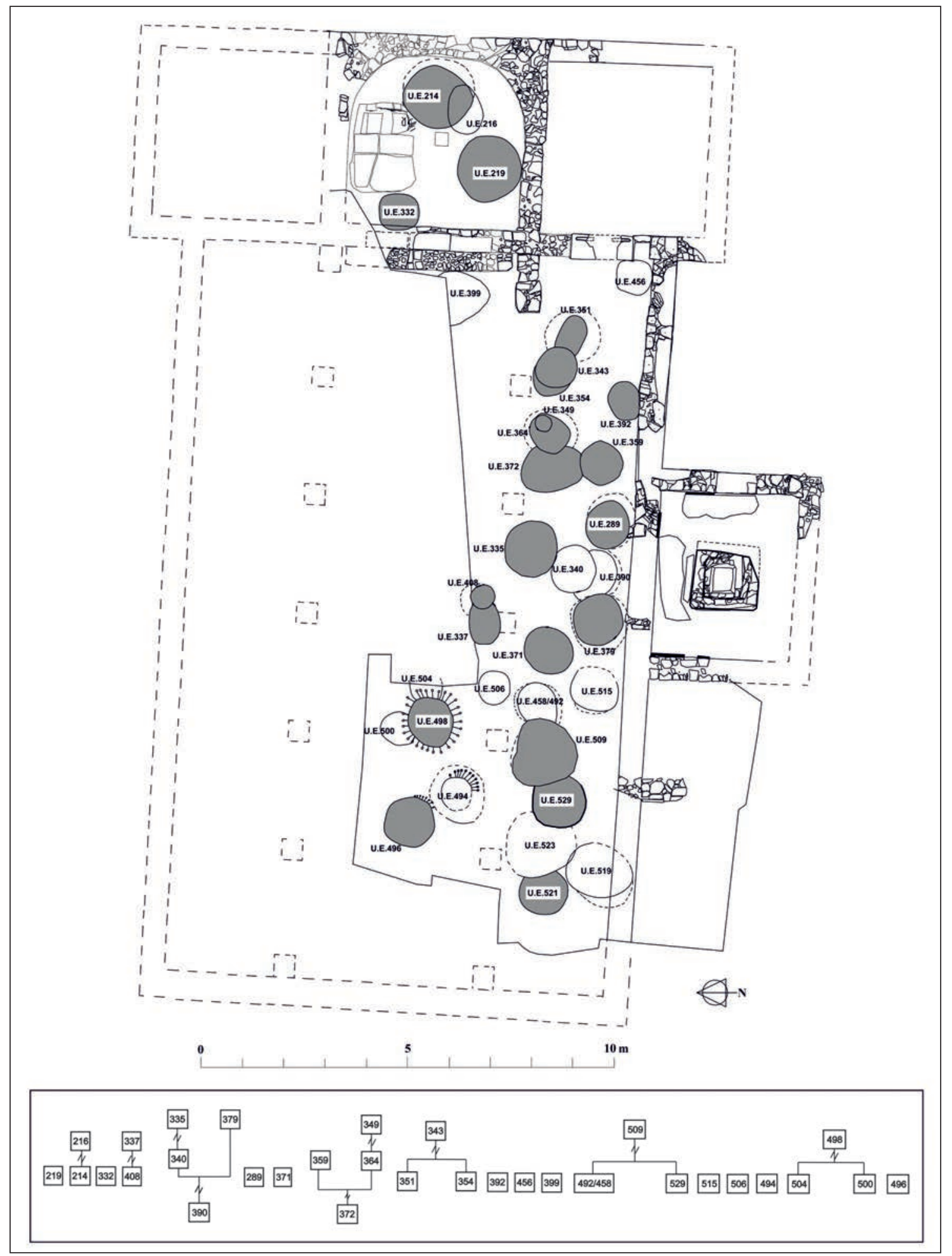

Figura 4. Planta de la basílica de San Martín con los silos documentados y diagrama estratigráfico. En gris se marcan los silos cuyos rellenos presentan materiales cerámicos que pegan entre sí. 


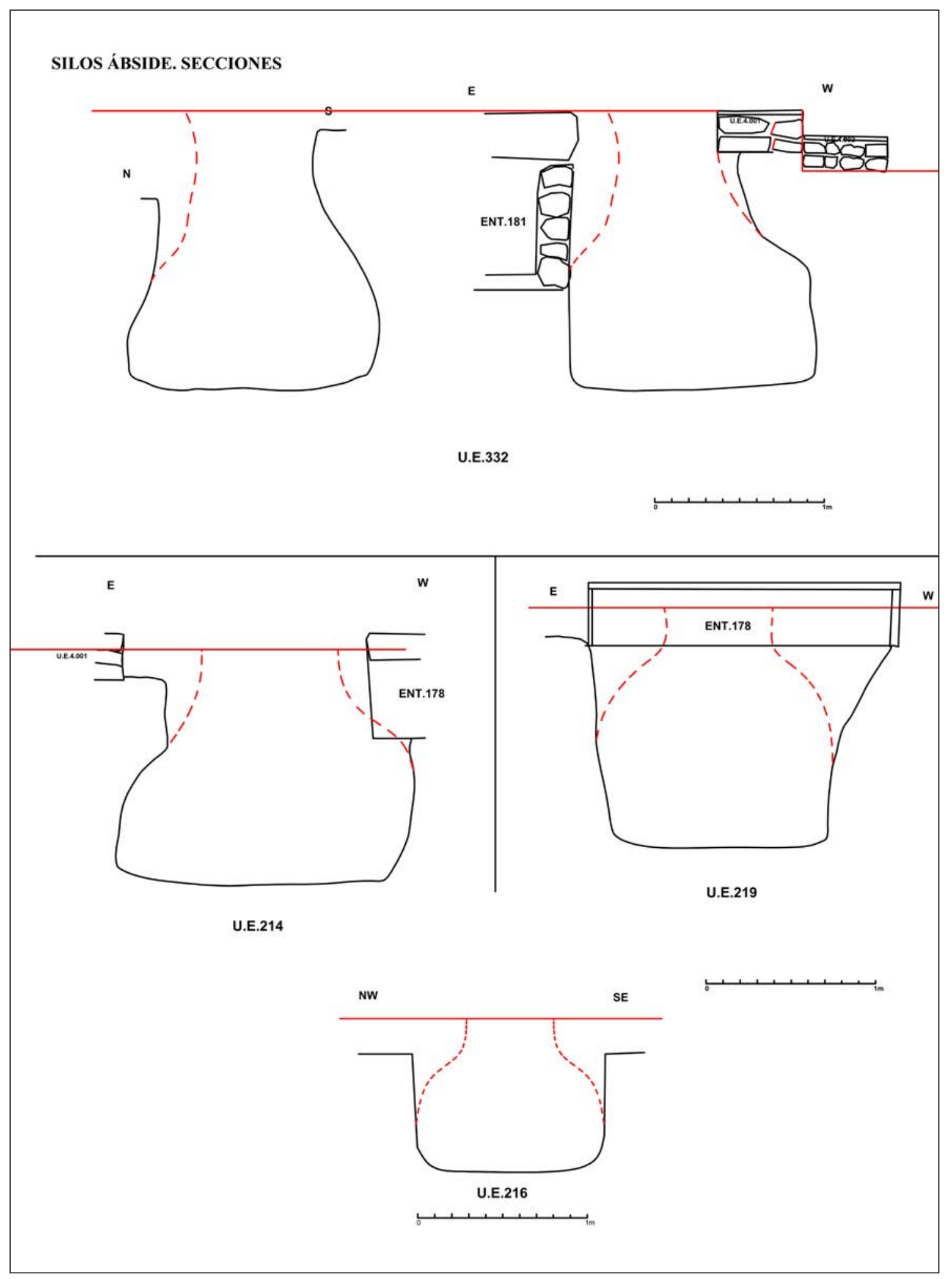

Figura 5. Secciones de los silos abiertos en el interior del ábside de la basílica. 


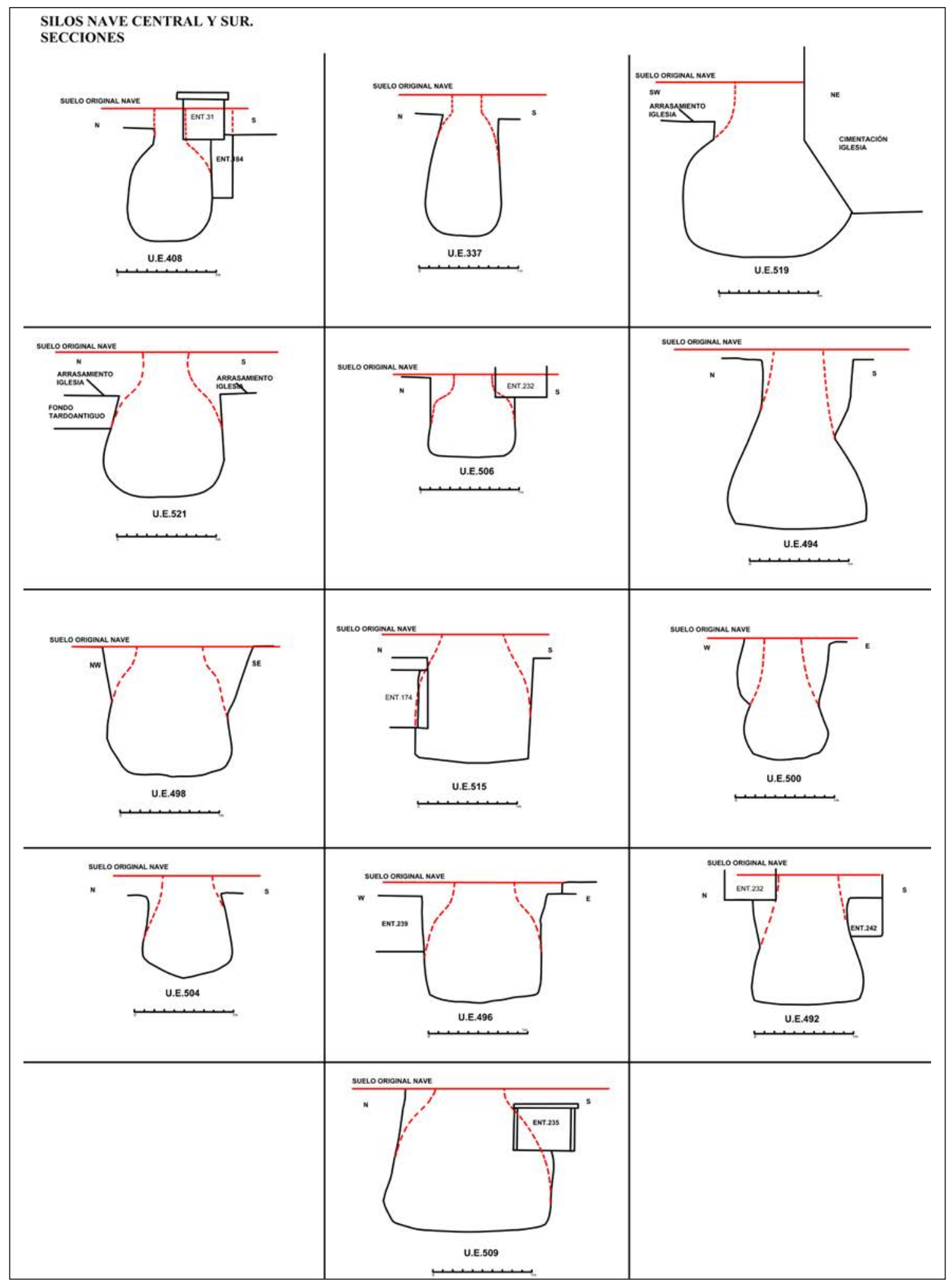

Figura 6. Secciones de los silos abiertos en el interior de la nave central y sur de la basílica. 


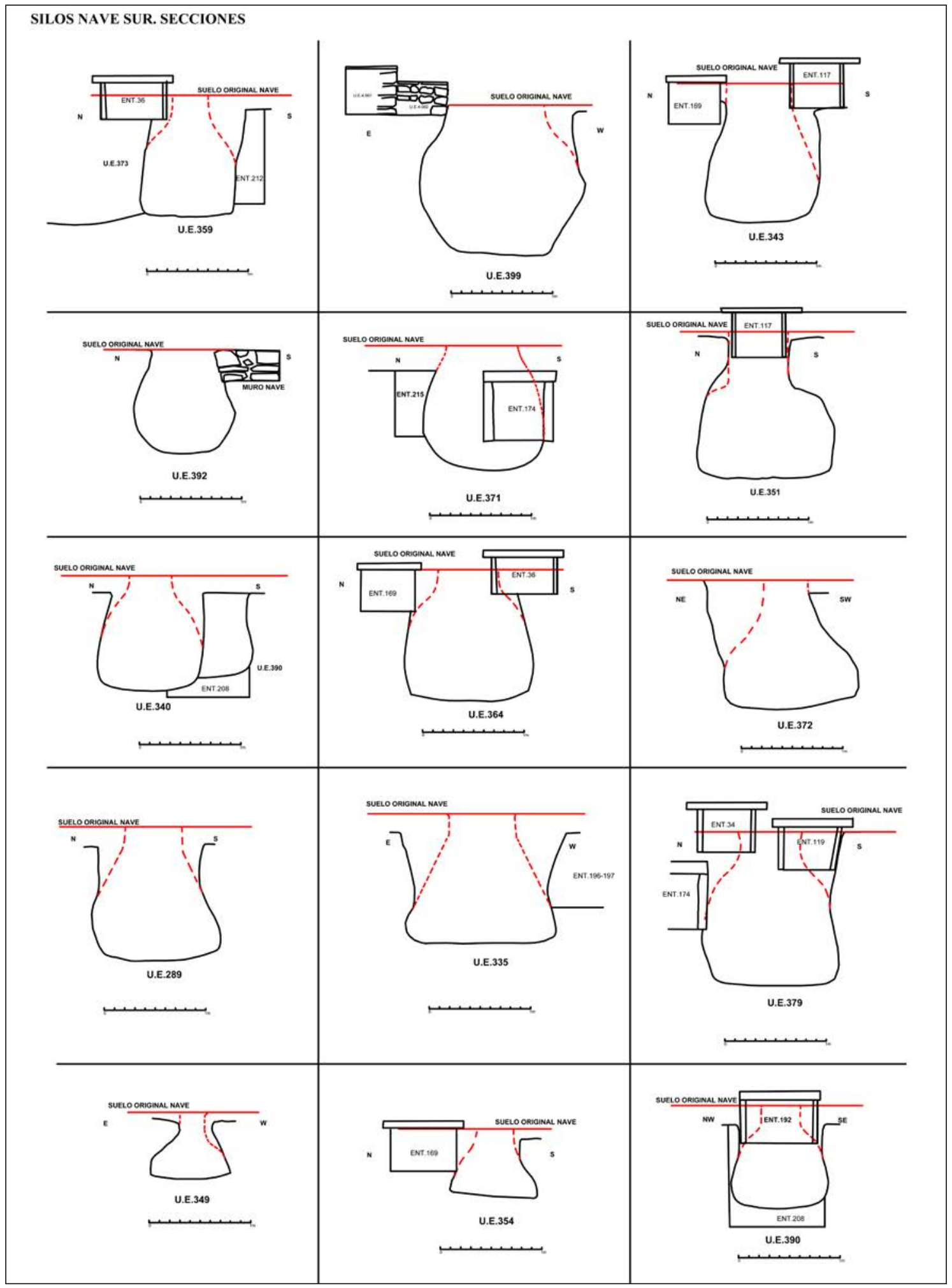

Figura 7. Secciones de los silos abiertos en el interior de la nave sur de la basílica. 
IGLESIAS, RENTAS Y SISTEMAS DE ALMACENAMIENTO EN EL PAÍS VASCO DURANTE LOS SIGLOS X Y XI... 257

\begin{tabular}{|c|c|c|c|c|c|c|c|c|}
\hline $\mathrm{UE}$ & $\begin{array}{l}\text { Relleno } \\
\text { por }\end{array}$ & $\begin{array}{l}\text { Diámetro } \\
\text { sup. } \\
\text { conservado }\end{array}$ & $\begin{array}{l}\text { Diámetro inf. } \\
\text { conservado }\end{array}$ & $\begin{array}{l}\text { Diámetro } \\
\text { máx. } \\
\text { conservado }\end{array}$ & $\begin{array}{c}\text { Altura } \\
\text { cons./estim. }\end{array}$ & $\begin{array}{l}\text { Volumen } \\
\text { cons. (L) }\end{array}$ & $\begin{array}{l}\text { Volumen } \\
\text { estim. (L) }\end{array}$ & Ubicación \\
\hline 214 & 213 & $143 \mathrm{~cm}$ & $162 \mathrm{~cm}$ & $170 \mathrm{~cm}$ & $120 / 140 \mathrm{~cm}$ & Muy alterado & ca.2.132 & Ábside \\
\hline 216 & 215 & $114 \mathrm{~cm}$ & $83 \mathrm{~cm}$ & $114 \mathrm{~cm}$ & $70 / 92 \mathrm{~cm}$ & 723 & ca.589 & Ábside \\
\hline 219 & 218 & $180 \mathrm{~cm}$ & $130 \mathrm{~cm}$ & $180 \mathrm{~cm}$ & $124 / 143 \mathrm{~cm}$ & Muy alterado & ca.1.418 & Ábside \\
\hline 332 & 331 & $81 \mathrm{~cm}$ & $143 \mathrm{~cm}$ & $147 \mathrm{~cm}$ & $165 / 165 \mathrm{~cm}$ & 1578 & ca.1.674 & Ábside \\
\hline 289 & 288 & $103 \mathrm{~cm}$ & $115 \mathrm{~cm}$ & $123 \mathrm{~cm}$ & $113 / 132$ & 1015 & ca.1.117 & Nave sur \\
\hline 335 & 393 & $165 \mathrm{~cm}$ & $141 \mathrm{~cm}$ & $165 \mathrm{~cm}$ & $97 / 128 \mathrm{~cm}$ & 1558 & ca.1.167 & Nave sur \\
\hline 337 & 336 & $56 \mathrm{~cm}$ & $76 \mathrm{~cm}$ & $43 \mathrm{~cm}$ & $123 / 144 \mathrm{~cm}$ & Muy alterado & ca.419 & Nave central \\
\hline 340 & 339 & $90 \mathrm{~cm}$ & $93 \mathrm{~cm}$ & $102 \mathrm{~cm}$ & $96 / 112 \mathrm{~cm}$ & 618 & ca. 620 & Nave sur \\
\hline 343 & 342 & $87 \mathrm{~cm}$ & $92 \mathrm{~cm}$ & $110 \mathrm{~m}$ & $110 / 137 \mathrm{~cm}$ & 820 & ca.912 & Nave sur \\
\hline 349 & 348 & $35 \mathrm{~cm}$ & $84 \mathrm{~cm}$ & $84 \mathrm{~cm}$ & $60 / 66 \mathrm{~cm}$ & 147 & ca.147 & Nave sur \\
\hline 351 & 352 & $60 \mathrm{~cm}$ & $134 \mathrm{~cm}$ & $134 \mathrm{~cm}$ & $140 / 146 \mathrm{~cm}$ & Muy alterado & ca.1.378 & Nave sur \\
\hline 354 & 353 & $64 \mathrm{~cm}$ & $85 \mathrm{~cm}$ & $85 \mathrm{~cm}$ & $58 / 67 \mathrm{~cm}$ & Muy alterado & ca. 217 & Nave sur \\
\hline 359 & 358 & $95 \mathrm{~cm}$ & $93 \mathrm{~cm}$ & $95 \mathrm{~m}$ & $91 / 120 \mathrm{~cm}$ & 682 & ca. 515 & Nave sur \\
\hline 364 & 363 & $95 \mathrm{~cm}$ & $117 \mathrm{~cm}$ & $127 \mathrm{~cm}$ & $121 / 130 \mathrm{~cm}$ & 1321 & ca.1.173 & Nave sur \\
\hline 371 & 370 & $90 \mathrm{~cm}$ & $85 \mathrm{~cm}$ & $120 \mathrm{~cm}$ & $99 / 124 \mathrm{~cm}$ & Muy alterado & ca.1.014 & Nave sur \\
\hline 372 & 373 & $102 \mathrm{~cm}$ & $132 \mathrm{~cm}$ & $132 \mathrm{~cm}$ & $128 / 128 \mathrm{~cm}$ & Muy alterado & ca. 867 & Nave sur \\
\hline 379 & 378 & $119 \mathrm{~cm}$ & $117 \mathrm{~cm}$ & $132 \mathrm{~cm}$ & $124 / 152 \mathrm{~cm}$ & Muy alterado & ca.1.331 & Nave sur \\
\hline 390 & 389 & $82 \mathrm{~cm}$ & $67 \mathrm{~cm}$ & $95 \mathrm{~cm}$ & $83 / 101 \mathrm{~cm}$ & Muy alterado & са. 460 & Nave sur \\
\hline 392 & 391 & $62 \mathrm{~cm}$ & $98 \mathrm{~cm}$ & $107 \mathrm{~cm}$ & $102 / 102 \mathrm{~cm}$ & 575 & ca. 575 & Nave sur \\
\hline 399 & 398 & $96 \mathrm{~cm}$ & $98 \mathrm{~cm}$ & $164 \mathrm{~cm}$ & $150 / 150 \mathrm{~cm}$ & 2316 & ca.2.225 & Nave central \\
\hline 408 & 407 & $58 \mathrm{~cm}$ & $52 \mathrm{~cm}$ & $84 \mathrm{~cm}$ & $115 / 135 \mathrm{~cm}$ & Muy alterado & ca. 451 & Nave central \\
\hline 456 & 455 & $\begin{array}{c}\text { Sin } \\
\text { determinar }\end{array}$ & $\begin{array}{c}\text { Sin } \\
\text { determinar }\end{array}$ & $\begin{array}{c}\text { Sin } \\
\text { determinar }\end{array}$ & Sin deter. & Sin deter. & Sin deter. & Nave sur \\
\hline $\begin{array}{l}458 \\
492 \\
\end{array}$ & $\begin{array}{l}457 \\
491 \\
\end{array}$ & $97 \mathrm{~cm}$ & $102 \mathrm{~cm}$ & $112 \mathrm{~cm}$ & $108 / 131 \mathrm{~cm}$ & Muy alterado & ca. 825 & Nave sur \\
\hline 494 & 493 & $91 \mathrm{~cm}$ & $132 \mathrm{~cm}$ & $140 \mathrm{~cm}$ & $172 / 181 \mathrm{~cm}$ & Muy alterado & ca.1.389 & Nave central \\
\hline 496 & 495 & $126 \mathrm{~cm}$ & $107 \mathrm{~cm}$ & $126 \mathrm{~cm}$ & $110 / 121 \mathrm{~cm}$ & 1180 & ca.943 & Nave central \\
\hline 498 & 497 & $152 \mathrm{~cm}$ & $77 \mathrm{~cm}$ & $152 \mathrm{~cm}$ & $131 / 131 \mathrm{~cm}$ & 1436 & ca.1.108 & Nave central \\
\hline 500 & 499 & $87 \mathrm{~cm}$ & $62 \mathrm{~cm}$ & $84 \mathrm{~cm}$ & $118 / 122 \mathrm{~cm}$ & Muy alterado & ca.411 & Nave central \\
\hline 504 & 503 & $76 \mathrm{~cm}$ & $88 \mathrm{~cm}$ & $90 \mathrm{~cm}$ & $83 / 106 \mathrm{~cm}$ & Muy alterado & ca.387 & Nave central \\
\hline 506 & 505 & $65 \mathrm{~cm}$ & $75 \mathrm{~cm}$ & $85 \mathrm{~cm}$ & $80 / 82 \mathrm{~cm}$ & Muy alterado & ca.348 & $\begin{array}{c}\text { Intercolumnio } \\
\text { entre naves }\end{array}$ \\
\hline 509 & 508 & $113 \mathrm{~cm}$ & $146 \mathrm{~cm}$ & $170 \mathrm{~cm}$ & $144 / 144 \mathrm{~cm}$ & Muy alterado & ca.2.298 & Nave sur \\
\hline 515 & 514 & $107 \mathrm{~cm}$ & $110 \mathrm{~cm}$ & $116 \mathrm{~cm}$ & $105 / 129 \mathrm{~cm}$ & Muy alterado & ca.969 & Nave sur \\
\hline 519 & 518 & $90 \mathrm{~cm}$ & $95 \mathrm{~cm}$ & $171 \mathrm{~cm}$ & $137 / 176 \mathrm{~cm}$ & Muy alterado & ca.2.543 & Nave sur \\
\hline 521 & 520 & $103 \mathrm{~cm}$ & $80 \mathrm{~cm}$ & $121 \mathrm{~cm}$ & $102 / 147 \mathrm{~cm}$ & Muy alterado & ca.982 & Nave sur \\
\hline 523 & 522 & $\begin{array}{c}\text { Sin } \\
\text { determinar }\end{array}$ & $\begin{array}{c}\text { Sin } \\
\text { determinar }\end{array}$ & $\begin{array}{c}\text { Sin } \\
\text { determinar }\end{array}$ & Sin deter. & Sin deter. & Sin deter. & Nave sur \\
\hline 529 & 528 & $\begin{array}{c}\text { Sin } \\
\text { determinar }\end{array}$ & $\begin{array}{c}\text { Sin } \\
\text { determinar }\end{array}$ & $\begin{array}{c}\text { Sin } \\
\text { determinar }\end{array}$ & Sin deter. & Sin deter. & Sin deter. & Nave sur \\
\hline
\end{tabular}

Figura 8. Dimensiones y capacidades de los silos localizados al interior de la basílica. 
podido realizar una estimación bastante fidedigna de su capacidad ${ }^{13}$. Así, se observa una gran variabilidad, existiendo grandes silos que superan ampliamente los 2.000 litros y otros, más pequeños, que no alcanzan los 150 litros (Fig. 8). En este sentido, no parece que exista una relación entre su tamaño y su situación en la iglesia, ya que se documentan aleatoriamente por todo el espacio disponible. Esta enorme variabilidad puede deberse a varias razones, pero parece probable que no fueron realizados siguiendo un plan preconcebido.

En cualquier caso, conviene destacar que durante el periodo de tiempo en el cual se utilizó el interior de la basílica como granero se pudo almacenar un volumen total estimado de $60.000 \operatorname{litros}^{14}$. Se trata de una cantidad muy considerable, siendo uno de los casos constatados a nivel peninsular con mayor volumen de acopio al interior de un edificio eclesiástico para esta cronología. No obstante, hay que tener en cuenta que todos los silos no funcionaron a la vez, sino que se fueron abriendo en un proceso diacrónico. De este modo, el volumen de grano almacenado al mismo tiempo no sería tan elevado. Nuestra atención, en consecuencia, debería centrarse en calcular el excedente que se pudo acumular de manera sincrónica. Lamentablemente, no es posible ni siquiera realizar una estimación, ya que resulta imposible computar los silos que funcionaron de manera simultánea y mucho menos deducir si todos los silos estuvieron rellenos de cereal hasta su embocadura. No obstante, el registro arqueológico indica que el periodo de uso no debió ser muy amplio, habiéndose abierto todos en un intervalo máximo de 200 años.

\subsection{Sobre CERÁmicas, DATACIONES y PROCESOS FORMATIVOS}

Cualquier arqueólogo que trabaje con procedimientos de excavación estratigráficos conoce que la cronología de los estratos deriva de dos componentes fundamentales. El aportado por la secuencia estratigráfica del yacimiento, que proporciona una datación relativa, y el aportado por los materiales contenidos

\footnotetext{
${ }^{13}$ En la tabla 3 se muestra el volumen real estimado de todos los silos. Para calcularlo se ha utilizado el programa de diseño gráfico asistido Autocad. En esta misma tabla, y en la medida que su estado de conservación lo permitía, también se indican los volúmenes conservados y se muestra gráficamente las importantes diferencias existentes entre la capacidad real del silo y lo que ha llegado a nosotros.

${ }^{14} \mathrm{La}$ capacidad estimada de los silos documentados es de 29.732 litros, pero como indicamos en una nota anterior, el número de silos existentes pudo doblar a los registrados en la intervención arqueológica. Y ello, suponiendo que los silos sólo se utilizaran una vez.
}

en los propios estratos, que facilitan su datación absoluta. Estratigráficamente sabíamos que todos los silos registrados al interior del templo eran posteriores a los enterramientos vestidos, datados entre la segunda mitad del siglo vi y el siglo viI, y anteriores a la construcción de la segunda iglesia y su correspondiente necrópolis, ambas datadas en la segunda mitad del siglo XII. Obteníamos así una horquilla cronológica situada entre el siglo viII y la primera mitad del siglo XII que resultaba prácticamente inservible por su extensión. Conscientes de la necesidad de constreñir este amplio hiato cronológico, procedimos al análisis del material cerámico contenido en los rellenos de amortización de los silos.

1. El estudio de la cerámica registró una mayoría de producciones vinculadas con las denominadas “cerámicas oxidantes sin manipular", integradas por los Grupos V y VI, con porcentajes parejos del $34 \%$ para cada uno. Junto a ellas aparecían las llamadas "cerámicas groseras manipuladas", identificadas con los Grupos I y II, que mostraban también importantes porcentajes del $9,5 \%$ y del $19,5 \%$ respectivamente ${ }^{15}$. A estas cerámicas de fabricación local se añadían dos producciones importadas de escasa representatividad $(\text { Grupos IX y } X)^{16}$.

El análisis estadístico descrito no casaba, sin embargo, con ninguno de los conjuntos cerámicos de referencia establecidos en trabajos anteriores (Solaun 2005 y 2013; Azkarate y Solaun 2016). Por un lado, la representación de los Grupos I y II (junto a la presencia del Grupo X) revelaba cronologías situadas en los siglos IX-X, si bien entraban en contradicción con los porcentajes detectados en los Grupos V y VI, los cuales apuntaban, por el contrario, al siglo XII.

Morfológicamente, las anomalías también eran evidentes. Aunque la mayoría de vasos documentados podían ser datados hasta fines del siglo XI o la primera mitad del siglo XII (Jarro 1.1, Jarros 4.1 y 4.2, Cántaro 1.1, Orzas 4 y 5), la forma más representada era la Olla 3 (en sus tres versiones, Olla 3-II, Olla 3-V y Olla 3-VI), con casi la mitad de las formas reconocibles, circunstancia que nos aproximaba nuevamente a contextos de los siglos IX-X. En la misma línea se manifestaban otras piezas menos representadas, pero no por ello menos indicativas, como las asociadas a los Grupos I y X (Cazuela 1, Olla 1 y Olla 8). Por el contrario, existían varias piezas del denominado

\footnotetext{
${ }^{15}$ Para una mayor información sobre estos dos grandes modos de producir cerámica (cerámicas oxidantes sin manipular y cerámicas groseras manipuladas), véase Azkarate y Solaun 2016.

${ }^{16}$ A estas producciones medievales cabe añadir la presencia de cerámicas tardoantiguas y romanas, en porcentajes que superaban el $7 \%$.
} 
Cántaro 2-V, cuya cronología retrasaba irremediablemente el conjunto cerámico hasta el siglo XI o la primera mitad del posterior siglo XII (Figs. 9 y 10).

Nos encontrábamos, por tanto, ante una ausencia de sincronía en el corpus cerámico que obligaba a repensar su datación y las circunstancias que dieron lugar a la formación de los estratos que lo contenían.

2. Conocer el modo en que los artefactos se presentan en el registro arqueológico constituye uno de los principales instrumentos para identificar los procesos deposicionales durante la ocupación, el abandono y el post-abandono de los yacimientos (Azkarate y Solaun 2013: 78-87). Del registro arqueológico exhumado en San Martín creemos no equivocarnos mucho al señalar que no existen depósitos en fase al interior de los silos; o, lo que es lo mismo, que los rellenos de los silos se formaron tras el abandono de las estructuras de almacenamiento, por lo que en ningún caso el material recuperado debe asociarse al uso original de ellas. Además, y en contra de lo que pudiera parecer, las destacadas tasas de material residual de los rellenos (importante asunto sobre el que más adelante volveremos), parecen descartar el uso de los silos como basureros, entendidos estos como lugares de descarte periódico. Todo apunta a que la gran mayoría de los rellenos se formaron como consecuencia de dos procesos deposicionales posteriores al abandono de los silos; los causados por acciones de construcción y destrucción.

- Depósito constructivo (Fig. 11.1). A diferencia del depósito de destrucción, este tipo de niveles está originado intencionadamente por el hombre y su formación obedece generalmente a la necesidad de nivelar, regularizar o preparar el terreno de cara a una posterior urbanización. En San Martín son la inmensa mayoría y pensamos que su depósito fue realizado principalmente con el objetivo de crear un suelo de obra que facilitase el metódico proceso de desmantelamiento del edificio eclesiástico ${ }^{17}$. Nos encontramos, por tanto, ante un depósito secundario en el que se mezclan materiales depositados en fase con otros residuales.

- Depósito de destrucción (derrumbe post-ocupacional) (Fig. 11.2). Con este término, acuñado por M. B. Schiffer (1988), nos referimos a la acción natural causada por efecto de erosiones o deslizamientos naturales del terreno que, en el caso de San Martín, provocaron el derrumbe parcial de las paredes de los

${ }^{17}$ Después de su abandono, el edificio eclesiástico será desmantelado en un proceso de disección, perfectamente organizado, con el objetivo de reaprovechar cada uno de sus materiales constructivos. De hecho, no será hasta la segunda mitad del siglo XII cuando, sobre su espacio, se construya la nueva iglesia de San Martín así como su nuevo cementerio. silos. Se trata de rellenos compuestos por las propias gravas y arcillas del sustrato geológico, sin apenas intrusiones, depositados siempre en la zona inferior del silo.

3. Durante el proceso de estudio nos apercibimos también de que muchos fragmentos cerámicos procedentes de los diferentes depósitos constructivos que rellenaban los silos pegaban entre sí, incluso con fragmentos recuperados en los rellenos de abandono de la basílica, lo que hacía coincidir el final de muchos silos con el del edificio religioso (Figs. 4 y 12). En concreto, de los 35 silos registrados al interior del templo, 22 contenían material asociable, situación de la que se pueden extraer dos importantes conclusiones. Por un lado, que la gran mayoría de silos fueron amortizados a la vez, de manera coetánea a la destrucción de la basílica. Es decir, que los silos que iban quedando en desuso no eran rellenados ${ }^{18}$, sino que permanecían vacíos, protegidos seguramente por una tarima de madera dotada de un sistema de cubiertas que permitía el acceso a ellos, al modo en que se disponían los entarimados de los cementerios parroquiales habilitados al interior de las iglesias ${ }^{19}$.

Por otro lado, que los rellenos de amortización de los silos fueron acarreados, casi con total seguridad, desde un basurero existente en las inmediaciones ${ }^{20}$. La análoga composición de estos rellenos, integrados mayoritariamente por restos cerámicos y constructivos (sillares, fragmentos de celosías y columnas), sugiere la presencia de un basurero consolidado que, atendiendo al patrón de gestión de los residuos, puede clasificarse como especializado (Azkarate y Solaun 2013: 83-85; Vigil-Escalera 2013: 135). Este tipo de basureros, situados generalmente a cielo abierto, origina contextos pluriestratificados de residuos que, al ser reaprovechados en actividades constructivas, forma depósitos con un alto grado de residualidad.

4. Y es precisamente este último aspecto, el de la residualidad, en el que creemos que se encuentra el origen de las anomalías detectadas en nuestro estudio cerámico. La presencia de basura secundaria utilizada como material de relleno de los silos produce estratos

\footnotetext{
${ }^{18}$ A excepción, lógicamente, de aquellos silos que fueron cortados para abrir otros nuevos en su misma posición, lo que obligatoriamente exigía el relleno previo de la estructura en desuso.

${ }^{19}$ Como ocurría en estos cementerios, la retirada de la cubierta ajustada en el entarimado permitía acceder a las sepulturas (en nuestro caso a los silos), no solo para realizar las labores propias de almacenado, sino para excavar nuevas estructuras subterráneas.

${ }^{20}$ En algunos casos, incluso, rellenos de silos cortados entre sí contenían fragmentos cerámicos de una misma pieza, hecho que puede ser interpretado como rellenos procedentes de un mismo basurero, pero depositados en distintos momentos cronológicos.
} 


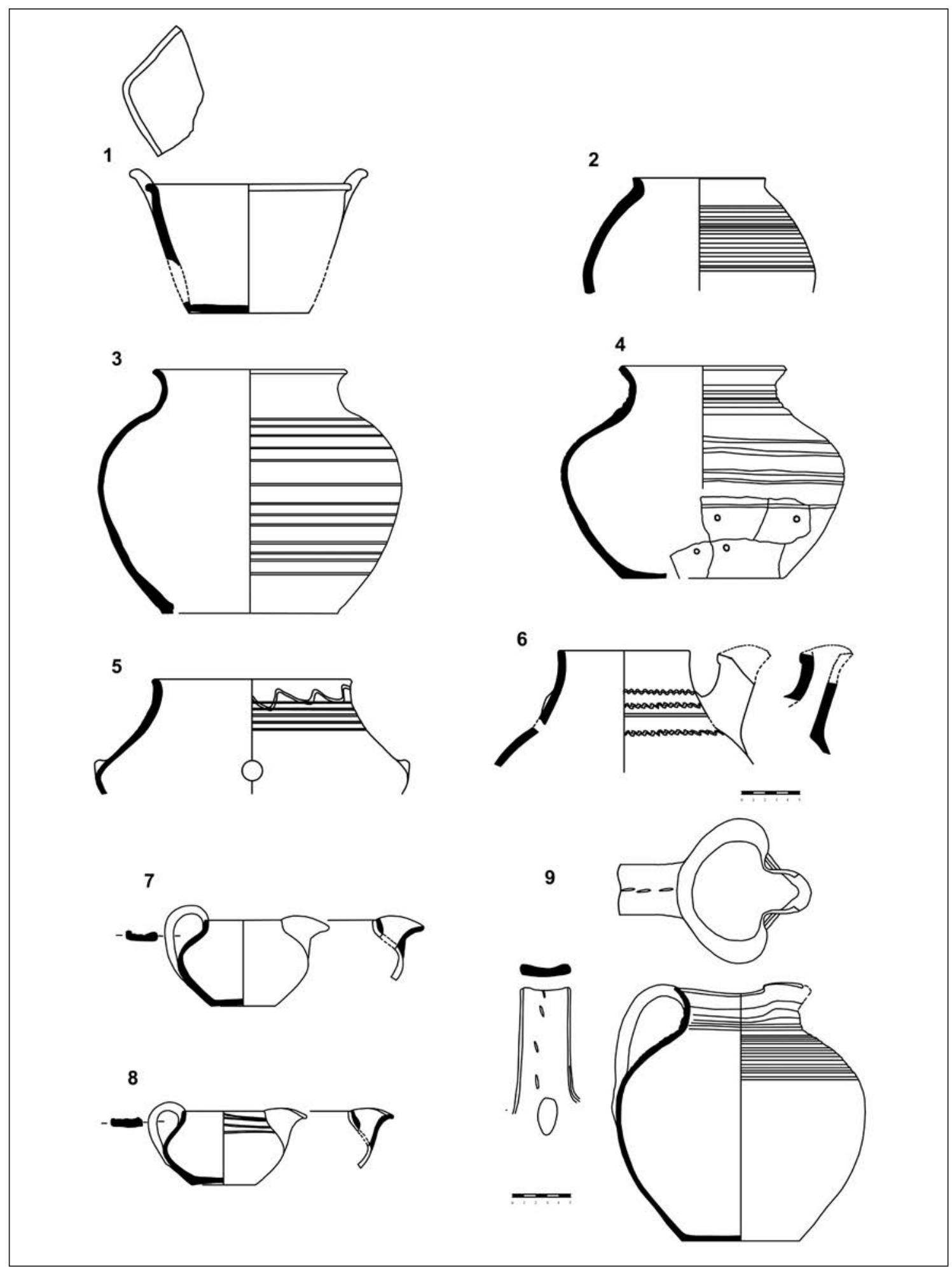

Figura 9. Imágenes de algunas de las cerámicas documentadas en los rellenos de los silos. 1. Cazuela 1-I; 2. Olla 1-I; 3-4. Olla 3-II; 5. Orza 4-VI; 6. Cántaro 2-VI; 7-8. Jarros 4.2-V y VI; 9. Cántaro 1.1-V. 


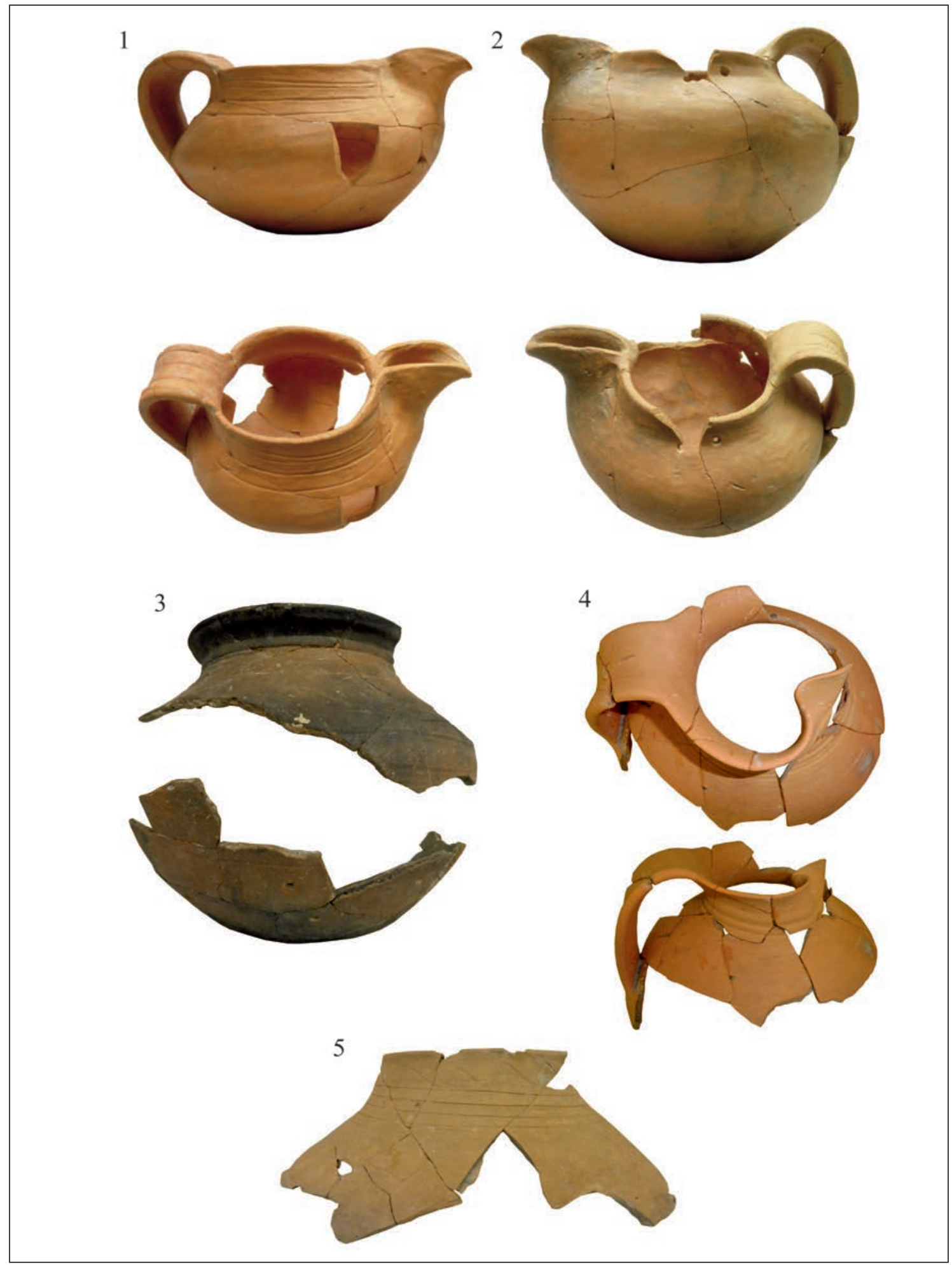

Figura 10. Imágenes de algunas de las cerámicas documentadas en los rellenos de los silos. 1-2. Jarro 4.2-V y VI; 3. Olla 3-II; 4. Cántaro 1.1-V; 5. Orza 4-VI. 


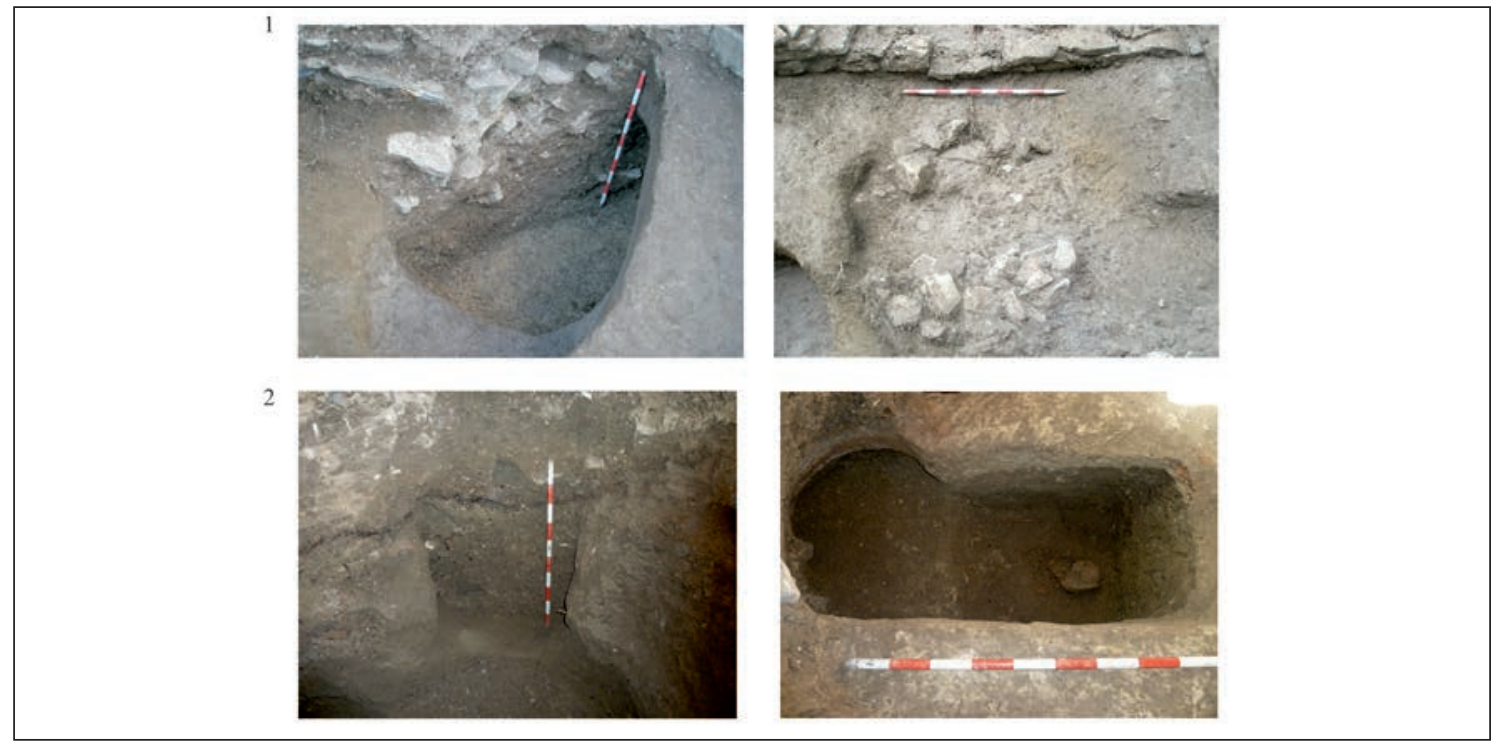

Figura 11. 1. Ejemplos de silos amortizados con rellenos constructivos; 2. Ejemplos de silos amortizados con rellenos procedentes del derrumbe de sus paredes.

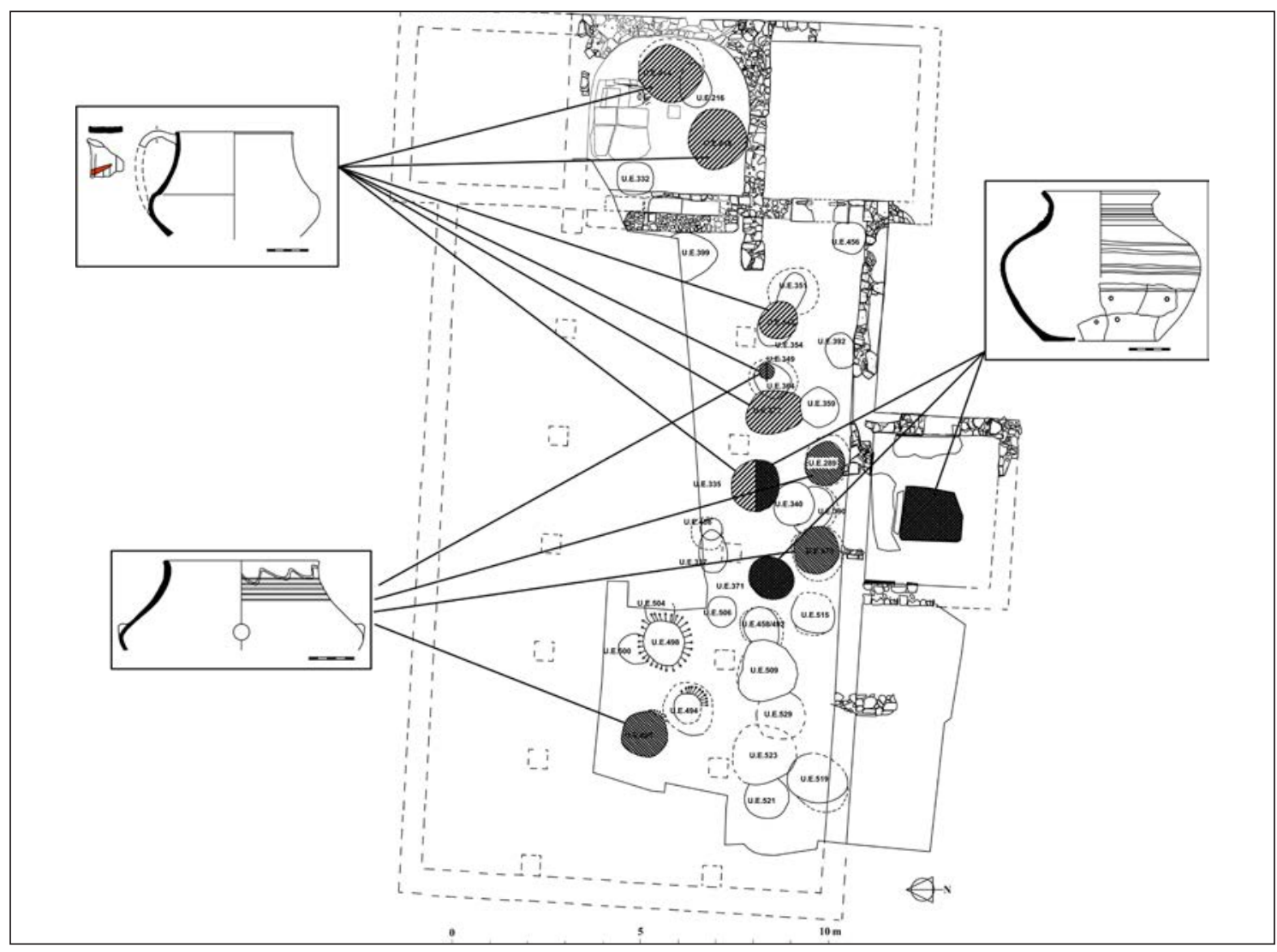

Figura 12. Planta de la basílica de San Martín en la que se señalan algunos rellenos de silos en los que se han recogido fragmentos cerámicos pertenecientes a una misma vasija. 
en los que se mezclan materiales en fase con otros residuales, distorsionando la datación proporcionada por la cerámica. En nuestro caso, como señalamos anteriormente, en un mismo estrato se mezclaban materiales de los siglos IX al XII, acompañados de otros de época romana y tardoantigua derivados de las primeras fases de ocupación del lugar.

No obstante, partiendo de que lo silos y sus rellenos son estratigráficamente anteriores a la construcción de la segunda iglesia (datada en la segunda mitad del siglo XII) y de que la datación absoluta de un estrato se establece en función del material datable más moderno contenido en el propio estrato y que le es coetáneo, siempre que no se trate de una intrusión (Carandini 1997: 36), podemos estimar el momento de amortización de los silos en el siglo XI o los primeros años del siglo XII, período en que se datan los materiales más modernos. Esta cronología, aunque no permite distinguir el proceso diacrónico completo mediante el cual se fueron abriendo los silos, sí permite considerar que estuvieron en uso hasta estas fechas.

Respecto al momento de apertura de los primeros silos, pensamos que su cronología no puede adelantarse más allá del siglo $\mathrm{x}$, muy posiblemente a las últimas décadas de esta centuria. El hecho de que la mayoría de los silos estratigráficamente más antiguos fueron rellenados con los mismos aportes de basura que los silos más tardíos sugiere un escaso margen de tiempo entre todos ellos, ya que las condiciones geológicas del terreno (graveras) provocan el rápido colapso de sus paredes. De hecho, aunque se registraron seis estructuras (uuee 390, 458/492, 494, 500, 504 y 506) amortizadas mayoritariamente por el derrumbe de las paredes (depósitos de destrucción), los escasos materiales cerámicos recuperados no permiten datarse nunca antes del siglo $\mathrm{x}$.

En definitiva, la ausencia de contextos cerámicos en fase anteriores a la décima centuria nos lleva a proponer una cronología para los silos situada entre los siglos x y XI.

\subsection{LOS SILOS Y SUS RELLENOS: LOS DATOS CARPO- LÓGICOS}

No queremos cerrar este capítulo sin hacer un breve comentario sobre los interesantes datos que ha proporcionado el estudio carpológico de los macrorrestos vegetales recuperados al interior de los silos ${ }^{21}$.

${ }^{21}$ El estudio carpológico está siendo realizado por Itsaso Sopelana. Queremos agradecer su disposición a la hora de proporcionar los datos necesarios para este trabajo.
Ya señalamos anteriormente que no parecen existir depósitos en fase rellenando estas estructuras, por lo que el material recuperado al interior no puede asociarse con el uso originario de los silos. Sus rellenos debieron ser mayoritariamente acarreados desde un basurero existente en las inmediaciones, en los que entremezclaban numerosos restos cerámicos, constructivos y, curiosamente, también vegetales. En efecto, sorprende sobremanera, la gran cantidad de semillas carbonizadas aparecidas en los rellenos de amortización que, aunque no podamos asociar fehacientemente con los cultivos almacenados en los silos, permiten reflexionar sobre los residuos existentes en proximidad a San Martín, gestionados y quizás pertenecientes a la propia iglesia.

El estudio carpológico determinó que el trigo era, con un $95 \%$ del registro total, el principal cereal, seguido muy de lejos por la cebada (2\%), el lino (2\%) y otros cultivos como el mijo, el panizo, la avena, las leguminosas y las plantas silvestres (1\%) (Fig. 13). Estos datos contrastan con los proporcionados por los rellenos de dos silos datados en el siglo VI, anteriores a la construcción de la basílica, en los que el mijo y el panizo, cereales de ciclo corto, son los más representados con un $85 \%$ del total. Por su parte, el trigo y la cebada apenas suponen el $15 \%$. Los datos también difieren de los obtenidos en otros contextos contemporáneos a Dulantzi. Por ejemplo, aunque en Gasteiz se documenta en los siglos XI y XII una profunda transformación en la estrategia agrícola, orientada a la disminución de la cebada y al progresivo aumento del trigo, el porcentaje de este último cereal nunca superará el 50\% (Azkarate et alii 2013: 432442). Los porcentajes de trigo son aún menores en otros asentamientos alaveses como Zaballa (Sopelana 2012: 452-478).

Todo apunta, en consecuencia, a una excepcional concentración de trigo en San Martín durante los siglos X y XI, un cereal enormemente valorado en transacciones y pagos en renta. No parece descabellado pensar, por lo tanto, que la gran proporción de trigo documentado en el yacimiento no sea consecuencia tanto de la estrategia agrícola desarrollada en Dulantzi, como del contexto privilegiado en el que se encuentra.

\section{INTERPRETACIÓN}

Como se ha referido más arriba, el presente trabajo arranca de las problemáticas aportadas en el congreso sobre "Horrea, Barns and Silos". Sobre dichos puntos de partida se ha definido el objetivo principal del trabajo: tratar de comprender el fenómeno de los silos asociados a las iglesias altomedievales, dentro 


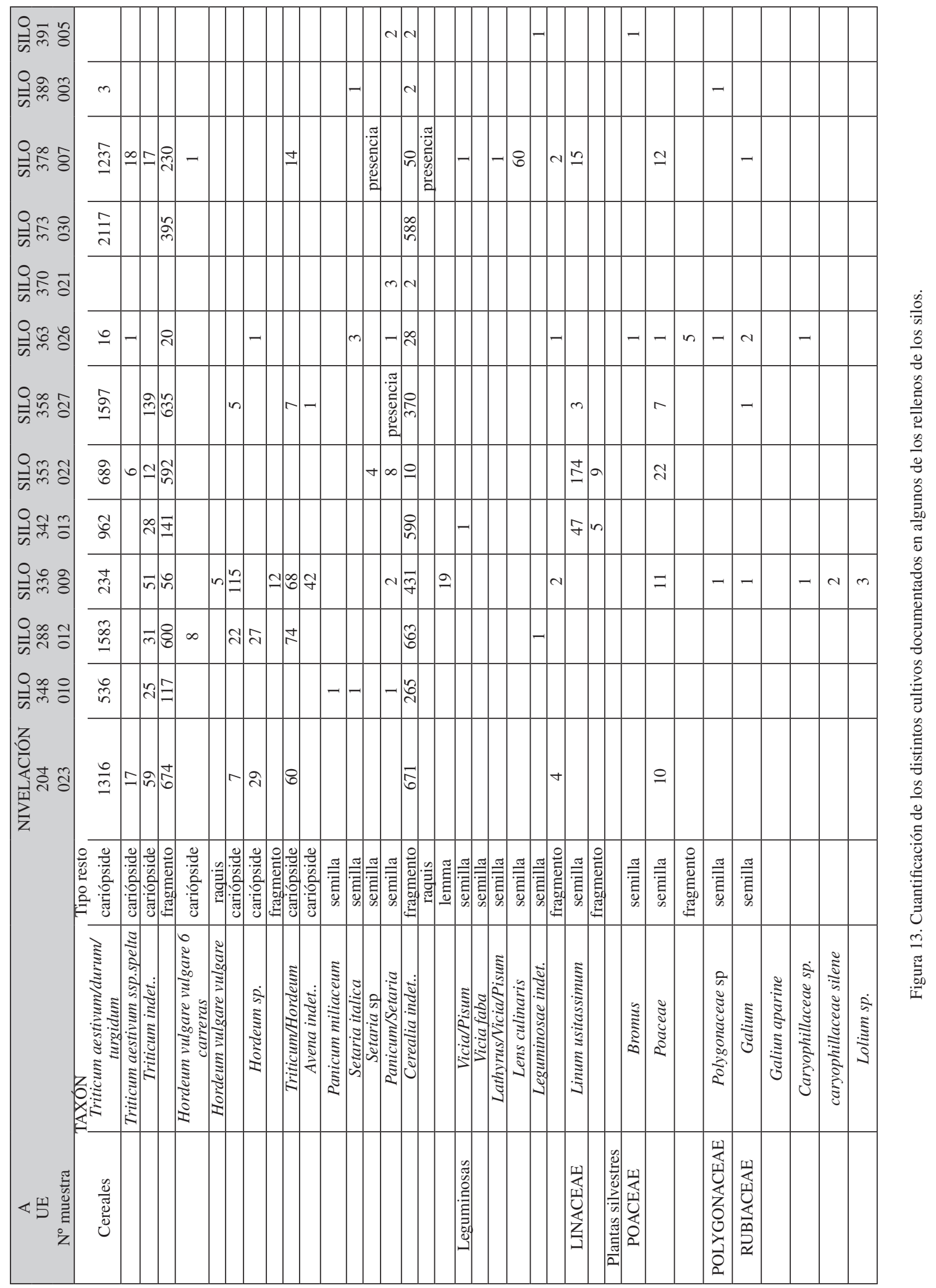


del marco peninsular, ejemplarizado en el templo de San Martín de Dulantzi. Esta necesaria contextualización y las consecuentes comparativas regionales resultan de gran importancia, dado que el País Vasco destaca precisamente por el reducido número de silos asociados a iglesias altomedievales. Un hecho, quizá explicable a partir de los escasos templos de dicha cronología intervenidos arqueológicamente de forma extensiva, circunstancia que ha dificultado la elaboración de propuestas interpretativas de carácter general (Quirós 2013: 184-186).

El hallazgo de los silos de San Martín de Dulantzi ha alterado este panorama yermo, aportando nuevos y valiosos datos que abren la puerta a la comprensión de la relación iglesias-silos en nuestro territorio. Para ello, sin embargo, es imprescindible llevar a cabo un esfuerzo interpretativo que justifique la apertura de tal cantidad de silos en la basílica durante el último siglo de su existencia. Dicho esfuerzo pretende dar respuesta a las siguientes cuestiones: ¿Quién lo hizo? ¿Por qué? ¿Cómo explicar la anomalía que representa San Martín en el contexto alavés y vasco en general?

La presencia de silos en San Martín se constata desde la Alta Edad Media. Sabemos con seguridad que algunos de ellos eran anteriores a la construcción de la basílica en los años centrales del siglo VI, pudiendo existir otros que también fueran previos o coetáneos a sus primeros momentos de uso, nunca superando el siglo vir. Estas estructuras subterráneas deben interpretarse, sin más problemas, como silos domésticos de almacenaje de la comunidad que vivía en Dulantzi, antes o durante la construcción de la basílica. El volumen de excedente que pudieron acumular es complicado de estimar, puesto que todas han llegado muy alteradas por la estratigrafía superior. De hecho, ni siquiera es posible establecer con seguridad el número exacto de silos en uso durante este momento. En cualquier caso, parece claro que dichas estructuras de almacenaje, junto con otros elementos de carácter doméstico, conformaron un importante hábitat altomedieval previo al edificio eclesiástico.

Durante los siglos VIII y IX no se registran silos en el yacimiento, si bien es posible que al exterior de la basílica, en algunas zonas no intervenidas, pudiera haberse abierto alguno. Quizá la presencia a partir del siglo viII de una extensa y densa necrópolis comunitaria condicionó el empleo de dichas estructuras. No obstante, y como veremos más adelante, la convivencia de funciones funerarias y de almacenaje en ciertos espacios no parece mostrar que dichos usos fueran mutuamente excluyentes.

Es a partir de las últimas décadas del siglo $\mathrm{x}$ cuando parecen documentarse los primeros silos en el interior del templo. Este hecho no coincide con ninguna reforma estructural en el edificio eclesiástico, que continúa desarrollando sus funciones litúrgicas. Su espacio circundante sigue además empleándose como cementerio comunitario y es en este momento cuando precisamente alcanzará su máxima extensión. Las sepulturas de dicha necrópolis conviven, de hecho, con otras estructuras domésticas, entre las que sobresale un conjunto de tres silos. Así pues, el único elemento discordante con el periodo anterior lo representan estas estructuras de almacenaje subterráneas, documentadas tanto en el exterior como, sobre todo, al interior del templo.

Hasta el momento se han detectado 35 silos en el interior del edificio de culto. Sabemos que todos no funcionaron de forma simultánea, sino que se fueron abriendo, utilizando y colmatando desde el siglo $\mathrm{x}$ hasta la ruina definitiva del templo en la primera mitad del siglo XII. Los indicios disponibles parecen sugerir, en efecto, que estas estructuras no se realizaron de manera coetánea, siguiendo un plan preconcebido, sino que se fueron abriendo en función de las necesidades del momento, aunque siempre en el interior del edificio. Este emplazamiento evidencia un notable interés, por parte de los propietarios del lugar, de almacenar siempre el excedente agrario en este limitado espacio, a pesar de las dificultades que dicha tarea pudiera conllevar.

Ahora bien, ¿cómo fue posible abrir un número tan elevado de silos en un edificio religioso en uso? Para responder a esta cuestión hay que acudir al capítulo anterior, destinado a entender el proceso formativo de los rellenos de amortización de los silos. Señalábamos aquí que la gran mayoría de silos fueron amortizados tras la ruina del templo, si bien muchos de ellos ya debían encontrarse en desuso. Así, los silos que se iban abandonando no eran posteriormente rellenados, sino que permanecían vacíos sin mayor problema; una circunstancia que solo puede entenderse con la presencia de una tarima de madera, dotada de un sistema de cubiertas, que permitía el desarrollo de las funciones cultuales en la basílica y, a su vez, el acceso a los silos. La presencia de este suelo flotante de madera haría innecesaria, al fin y al cabo, la amortización de los silos tras su abandono, a excepción de aquellos que iban a ser afectados por la apertura de otro en su misma posición.

\section{1. ¿QUIÉN?}

Si bien se desconoce la naturaleza de los propietarios del templo en el momento de su fundación, pudiendo ser de naturaleza episcopal (Larrea 2016) 
o privada ${ }^{22}$, las evidencias materiales sugieren un control exclusivamente señorial para el siglo x. Ello no implica, por supuesto, que el control por parte de poderes privados no pueda ser anterior, sino que es en este siglo cuando estamos en condiciones de identificarlo sin demasiados problemas.

Con iglesia señorial nos referimos, por tanto, a aquellos templos controlados por poderes privados, en contraposición a los dominados por la jerarquía diocesana y considerados públicos. Este significado es independiente a la naturaleza de los propietarios, que podían ser laicos (familias nobiliares, monarquía o comunidades aldeanas) o religiosos (monasterios $\mathrm{u}$ órdenes militares). Fundaban estas iglesias con intereses materiales y espirituales y las donaban, compraban y enajenaban como cualquier otra propiedad.

En ocasiones incluso estos poderes laicos y religiosos se confundían, siendo difícil poder establecer una neta diferenciación entre ambos, al menos durante la Alta Edad Media y hasta el siglo XI. De hecho, F. J. Fernández Conde define su cuarto modelo de monacato altomedieval a partir de miembros destacados de familias importantes que fundan iglesias/ cenobios, viviendo en ellas como si fueran monjes, aunque sin someterse en la práctica a ninguna regla y empleándolas como instrumentos para cohesionar y aumentar su patrimonio (Fernández Conde 2000: 276-277).

Por otro lado, tampoco parece existir para estos siglos, salvo casos puntuales, la nítida diferenciación entre clero regular y secular que sí se constata a partir del siglo XII. Así lo consideran diversos medievalistas. R. Sharpe advierte que "debemos intentar evitar exagerar la distinción entre comunidades regulares y seculares" (Sharpe 1992: 101-102), mientras que J. Á. García de Cortázar considera que antes de mediados del siglo XI resulta difícil distinguir, salvo casos concretos, el papel de multitud de monasterios con pequeñas y escasamente reguladas comunidades, de templos parroquiales o de otras unidades de convivencia y explotación del territorio (García de Cortázar 2008: 29). F. J. Fernández Conde, por su parte, va algo más allá: "Quizá en este período — siglos VIII y $\mathrm{X}$ - resulte impropio o anacrónico hablar de clero regular y secular en cuanto realidades eclesiásticas contradistintas. Sólo más tarde, cuando se definan perfectamente los límites entre iglesia o monasterio

\footnotetext{
${ }^{22}$ Un reciente artículo sobre el evergetismo episcopal de los siglos VI y VII en Hispania rebaja la importancia de los obispos en la edificación de iglesias en zonas rurales, poniendo el acento en la iniciativa privada: "[...] it was the laypeople who in those early days footed the bill for the building of rural churches with their own incomes, through voluntary pious acts" (Utrero y Moreno 2015: 129-130).
}

propios, monasterio sub regula e iglesia de aldea propiamente dicha, que hoy denominaríamos iglesia secular, podremos hablar, con propiedad, de un verdadero dualismo eclesiástico" (Fernández Conde 2000: 277).

Todo esto complica el reconocimiento y la adecuada comprensión de los poderes que controlaban San Martín de Dulantzi en el siglo x, más allá de que eran privados y del carácter eminentemente familiar con el que entendían sus propiedades ${ }^{23}$.

En cualquier caso, el hiato que se produce entre el desmantelamiento de la vieja iglesia a finales del siglo XI o a comienzos del siglo XII y la construcción del nuevo templo unas décadas más tarde es un buen indicador del carácter privado de la primera hasta ese momento. Después de todo, el hecho de que los habitantes de Dulantzi no contaran con este edificio de culto en la aldea para recibir sus sacramentos durante dicho intervalo refleja que la cura de almas que ofrecía a la comunidad había tenido siempre un carácter secundario. La vieja iglesia fue ante todo una iglesia señorial. Por ello, cuando la familia que la había instrumentalizado desapareció o dejó de necesitarla, bien porque ya no era rentable, bien porque cambiaron las formas de representación del poder, acabó arruinándose.

Asimismo, no parece casual que la apertura de los silos en el interior del templo se produjera en el siglo $\mathrm{x}$, momento en el que se documentan diversas fundaciones de iglesias señoriales en Álava. Los templos identificados en los yacimientos de Aistra y Zaballa $^{24}$, así como los del grupo 3 definido por L. Sánchez Zufiaurre ${ }^{25}$ parecen reflejar la emergencia de poderes supralocales que emplean los edificios de culto con funciones religiosas (lograr la salvación

\footnotetext{
${ }^{23}$ En su trabajo sobre las donaciones del siglo $\mathrm{x}$ en el norte de la península ibérica, W. Davies afirma que toda colección de esta centuria evidencia el control por parte de las familias de iglesias y monasterios (Davies, 2007, 42-43).

${ }^{24}$ Tanto en Aistra como en Zaballa la construcción del templo implicó una ruptura tal del ambiente técnico (Bianchi 1996) y de la organización espacial preexistente que permite asegurar, sin demasiadas dudas, la participación de estos poderes (Alfaro 2016: 79-80, 90-92).

${ }^{25}$ Hacemos referencia sólo a este grupo porque es el único de los diferenciados por el arqueólogo argentino que se circunscribe de forma exclusiva al siglo $\mathrm{x}$, destacando además por su sistema productivo de cantería (Sánchez Zufiaurre 2007: 272-274). Con todo, es bastante probable que algunas de las iglesias de los grupos 2 (ss. IX-X) y 4 (ss. X-XII), puedan identificarse también con este mismo proceso histórico, independientemente de que reflejen una menor participación de canteros. A fin de cuentas consideramos, a tenor de las evidencias disponibles, que la construcción de iglesias antes del siglo XII estuvo liderada mayoritariamente por poderes nobiliares y monasteriales, sin que ello excluya la posibilidad de que elites o las propias comunidades aldeanas pudieran hacerlo de forma puntual.
} 
de sus almas), económicas (cohesionar, aumentar y asegurar su patrimonio), de prestigio y estatus y como instrumento para introducirse en las propias comunidades rurales (diferenciación social y perpetuación de su memoria) (Fernández Conde 2000: 276-277; Wood 2006: 445; Davies 2007: 215-216; Larrea 2007; Azkarate y García Camino 2012: 345-346).

El análisis de la documentación escrita confirma el control señorial y monasterial de las iglesias alavesas en este momento. Un diploma de Fortunio, último obispo de Álava, fechado en 1085, en el que renuncia a diversos derechos a favor del monasterio de San Juan de la Peña (De Mañaricua 1964: 139) y el acuerdo del obispo de Calahorra, Sancho de Grañón, de principios del siglo XII (Llorente 1808: 7-10), dan perfecta cuenta de que las iglesias, más allá del plano teórico, estaban ajenas a la autoridad diocesana.

El escenario comenzó a cambiar en la primera mitad del siglo XII, siendo el punto de inflexión el diploma de 1135 firmado por el obispo de Calahorra Sancho de Funes. En éste se establecía de forma efectiva el arcedianato de Álava y la percepción de rentas en iglesias del entorno en lo que parecen ser los primeros esbozos de una jerarquía administrativa diocesana en territorio alavés (Carl 2011: 150-151; Sáenz de Haro 2012: 466).

No obstante, el proceso de expansión y consolidación de los poderes episcopales en Álava fue largo y difícil, extendiéndose durante ese siglo y buena parte del siguiente. De hecho, todavía a finales del siglo XII había que entender el mapa de iglesias el Álava como un complejo tapiz en el que se interrelacionaban de forma continua y dinámica los poderes episcopal, monástico y nobiliar, en no pocas ocasiones de forma conflictiva. En este enrevesado escenario era posible tanto que el obispo arrendase el cobro de sus rentas a la nobleza ${ }^{26}$ como que un papa regulase las parroquias integradas en dominios monasteriales, como hizo Celestino III en el decálogo de derecho canónico diocesano que promulgaba una bula de $1192^{27}$.

La debilidad del poder diocesano, incapaz todavía de imponerse sobre el resto de actores en liza, es visible en otras disposiciones de dicho decálogo: la

\footnotetext{
${ }^{26}$ El documento de 1173 entre Gonzalo de Hornillos y e obispo Rodrigo de Cascante (Llorente 1808: 211-212) es indicador de unas prácticas que sobrevivieron al cambio de siglo, como evidencian los diplomas de Diego López de Haro de 1229 (Rodríguez R. de Lama 1989: 92-93) o Iñigo de Mendoza de 1240 (Rodríguez R. de Lama 1989: 135-137).

${ }^{27}$ Su punto 8 dice así: "En las iglesias parroquiales que, en el obispado de Calahorra, tenían los monjes, no se coloquen presbiterios sin permiso de los obispos de esta sede y, cuando queden vacantes, los abades y priores monacales presenten previamente al obispo a los presbíteros sustitutos" (Sáinz Ripa 1994: 389-390; Rodríguez R. de Lama 1979: 109-112).
}

prohibición de edificar capillas u oratorios (punto 3) o distraer, vender, enajenar o hipotecar bienes de una iglesia (punto 4) sin permiso del obispo, así como la exhortación a los laicos de no imponer a las iglesias nuevos gravámenes (punto 6) (Sáinz Ripa 1994: 389390; Rodríguez R. de Lama 1979: 109-112).

Hasta la segunda mitad del siglo XIII no estamos en condiciones de afirmar que los poderes diocesanos controlasen en Álava las iglesias del mundo local. Fue la concordia de 1257 entre el obispo de Calahorra Jerónimo Aznar y los clérigos de su cabildo catedralicio la que muestra por vez primera los profundos cambios acaecidos sobre el panorama anterior. En ella se mencionan nada menos que 424 templos alaveses plenamente articulados en la jerarquía diocesana (arciprestazgos y arcedianatos) y que pagaban los impuestos eclesiásticos exigidos (Rodríguez R. de Lama 1989).

La documentación escrita refleja con claridad, por lo tanto, que los poderes diocesanos no se impusieron en Álava de forma rotunda hasta bien entrado el siglo XIII y que hasta ese momento pervivió el modelo basado en iglesias propias que hundía sus raíces en la Alta Edad Media.

Todos estos indicios sugieren, en definitiva, que San Martín era en el siglo x una iglesia señorial asociada a una familia de cierta entidad territorial. Pero, ¿qué papel jugaron en este contexto los silos de almacenaje abiertos en su interior a partir de la segunda mitad de esa centuria? ¿Cuál fue la razón de que la iglesia adquiriese una nueva función de almacenamiento complementaria a la actividad litúrgica?

\section{2. ¿POR QUÉ?}

Es importante precisar, tal y como hemos adelantado más arriba, que son pocos los silos que se han identificado asociados a iglesias en el País Vasco (Quirós 2013: 184). En Álava apenas se conocen una veintena de estas estructuras en edificios religiosos, de las que sólo ocho se ubican en el interior ${ }^{28}$. El dato resulta relevante por dos motivos. Primero, porque evidencia las sustanciales diferencias de Álava con otros territorios peninsulares, como Cataluña, donde los silos tuvieron una presencia mucho mayor en contextos eclesiales. Estas diferencias, junto a la pre-

\footnotetext{
${ }^{28}$ Cinco en San Tirso de Zaballa (Quirós 2012), dos en San Román de Tobillas (Azkarate 1995), cuatro en la ermita de Santa Eufemia de Maeztu (Sáenz de Urturi 1990), tres en Los Castros de Lastra (Sáenz de Urturi 1985; 1986; 1988), cinco en la basílica de San Prudencio de Armentia (Lasagabaster et alii 2006) y uno en la ermita de San Martín en Salvatierra (Fernández de Jauregui 2005).
} 
sencia de sagreras o de poderes episcopales fuertes en cronologías tempranas, reflejan el desarrollo de otros procesos históricos en la Marca Hispánica y, en consecuencia, la incapacidad de importar de forma mecánica sus modelos interpretativos.

De hecho, a primera vista podría decirse que San Martín de Dulantzi se asemeja a ciertos yacimientos catalanes, como la iglesia vieja de Sant Menna en Senmanat, Barcelona (Coll et alii 2001). Pero si tenemos en cuenta las particulares características del territorio, estos parecidos no son más que aparentes. El ensagrerament, un fenómeno clave de la historia medieval catalana, no parece que haya tenido apenas influencia en el País Vasco ${ }^{29}$. Asimismo, y como se ha explicado en el apartado anterior, tampoco existen poderes episcopales fuertes en la zona, mientras que la creación de las sagreras, parroquias y el comienzo de la percepción de rentas eclesiásticas se identifica en Cataluña con iniciativas episcopales. Así, R. Martí cifra en más de 276 las actas de consagración y dotación de iglesias que lideran obispos catalanes entre los siglos IX y XI (Martí 2006: 155-157), algo sin parangón en nuestro marco geográfico ${ }^{30}$.

Segundo, porque la escasez de silos asociados a iglesias alavesas subraya la excepcionalidad del caso de Dulantzi. Parece que los propietarios de las iglesias señoriales alavesas prefirieron otro tipo de sistemas de almacenaje frente al silo excavado en el suelo. Es probable que las rentas ligadas a estos templos se guardaran en estructuras adosadas en materiales perecederos, como sugirió L. Sánchez a partir de las ménsulas identificadas en los muros norte y oeste de las iglesias de su grupo 4 (Sánchez Zufiaurre 2007: 291, 328). Por lo tanto, la singularidad de Dulantzi se debe, no sólo a la apertura de silos en el interior del templo, sino sobre todo a la profusión con la que se desarrolló dicha tarea. Los treinta y cinco silos hallados en su interior, habiendo podido excavar sólo la mitad meridional del templo, dan fe del profun-

\footnotetext{
${ }^{29}$ Aunque se haya identificado algún dextro, como en la localidad alavesa de Gopegi, o se haga mención a ellos en la documentación (Sánchez Zufiaurre 2007: 140) no se evidencian las consecuencias sociales y económicas que el fenómeno tuvo en Cataluña.

${ }^{30}$ Con todo, es importante subrayar que la titularidad y el control diezmal por parte de actores privados no fue algo totalmente ajeno al territorio catalán, a pesar de la importancia que alcanzaron aquí los poderes episcopales. En el caso del Rosellón, y a diferencia de los condados al sur de los Pirineos, no parece que los cellers (equivalente de las sagreras) sigan una iniciativa episcopal, sino que fueron instrumentalizados de forma exclusiva por los señores, tanto laicos como eclesiásticos (Catafau 2007: 216-217). Por otro lado, tampoco los investigadores de la Cataluña peninsular han negado cierta influencia, siempre matizada, de la iniciativa privada (Villaginés 1988: 136-139; Martí 2006: 157; Farias 2007: 75).
}

do contraste existente con el resto de evidencias del marco alavés.

La ausencia de documentación escrita compromete sobremanera la tarea de definir la naturaleza de los excedentes que se almacenaban en estas estructuras. Podrían provenir tanto de las rentas asociadas al propio templo, como tratarse específicamente de censos eclesiásticos, que podrían además haber sido aportados de forma voluntaria o ser parte de un sistema de captación obligatorio. Del mismo modo, los silos y graneros reflejan sólo una parte de los censos eclesiásticos. En los textos se diferencia el diezmo mayor (granado), que se entregaba fundamentalmente en especie (el pan, la producción cerealística y, en aquellas regiones donde se produjesen, el vino, la producción ganadera o el lino) y el diezmo menor (menucias), que solía pagarse con dinero y que diezmaban otros productos menos rentables y duraderos como los hortícolas y frutales. También se mencionan otros censos como las ofrendas a pie de altar, las primicias, las cuarentenas, los mortuorios y las cenas (Fernández Conde 1987: 77-79; Díaz de Durana y Guinot 2010: 71).

Con todo, y pese a estas limitaciones, es factible que los silos abiertos en San Martín evidencien la captación y almacenamiento del diezmo mayor por parte de la familia propietaria del templo. Así lo sugiere la clara intención de emplear como lugar de almacenaje el espacio interior de la iglesia ${ }^{31}$. Un empeño por el que prácticamente agotaron todo el espacio útil del edificio de culto y que sugiere una finalidad legitimadora. En un momento en que la familia propietaria no contaba con un relato consolidado para justificar el pago de censos eclesiásticos, como sí tuvo unos siglos más adelante la Iglesia a través de la institución parroquial, aprovecharon la importancia del lugar físico y sagrado ${ }^{32}$. Al fin y al cabo, las rentas se pagaban y se guardaban en la iglesia porque eran dadas a Dios, como proveedor de todos los bienes que tenían las gentes de este mundo (Díaz de Durana y Guinot 2010: 69).

No obstante, parece poco probable que se tratase de una red cerrada en la que la apropiación de dichas rentas se fijase bajo términos territoriales, como

\footnotetext{
${ }^{31}$ Igualmente, los citados datos carpológicos, en los que el trigo supone el $95 \%$ de una amplia muestra de cereales (véase epígrafe: Los silos y sus rellenos: los datos carpológicos), podrían apuntar en esta misma dirección. De todos modos, la naturaleza secundaria de los depósitos aconseja emplear esta información con cautela.

${ }^{32}$ La identificación de los silos en el interior de iglesias con el almacenaje de censos eclesiásticos ya fue propuesta para ámbito catalán (Martí 2007: 195). No obstante, las diferencias interpretativas entre los silos interiores y exteriores se basan en el marco teórico del ensagrerament que, como ya se ha dicho, es difícilmente exportable a nuestro territorio.
} 
ocurrió con la parroquia. El documento de Sancho de Grañón, al que hemos hecho referencia más arriba, muestra que los individuos podían recibir servicios pastorales en un templo y pagar los censos eclesiásticos en otro diferente ${ }^{33}$.

La singularidad de este yacimiento en nuestro territorio impone, para concluir, una pregunta obligada: ¿fue Dulantzi la excepción o la regla? Esto es, ¿podríamos aventurar en ámbito alavés un origen señorial $\mathrm{y}$ anterior a la parroquia del diezmo y de otras rentas eclesiásticas? Difícilmente, la verdad. En el curso actual de las investigaciones, con el escaso número de silos hallado y los problemas para identificar otro tipo de estructuras de almacenaje, no es posible ir más allá. Existen indicios que apuntan con cierta seguridad a que este modelo primigenio de percepción diezmal sin connotaciones territoriales pudo desarrollarse en Dulantzi, pero nada más. Desconocemos si se trata de una excepción, lo que explicaría el carácter atípico del yacimiento y quizá el poder y ámbito de influencia de sus propietarios, o de una regla, con lo que otras familias también percibieron estas rentas en sus iglesias, almacenándolas en graneros u hórreos que no hemos sido capaces de reconocer. Será, en cualquier caso, la información aportada por las futuras investigaciones la que permitirá resolver dicho interrogante.

\section{AGRADECIMIENTOS}

Este trabajo se ha realizado en el marco de la actividad investigadora del Grupo de Investigación en Patrimonio y Paisajes Culturales (IT931-16) y del Grupo de Investigación en Patrimonio Construido (IT890-16) de la Universidad del País Vasco UPV/EHU. Asimismo, los autores desean agradecer al Departamento de Euskera, Cultura y Deporte de la Diputación Foral de Álava por su financiación del estudio carpológico.

\section{BIBLIOGRAFÍA}

Alfaro, E. 2016: La formación de la red parroquial en Álava y Treviño. Evidencias desde la arqueología (siglos XI-XIII),

\footnotetext{
33 "Los señores juraron que no acosarían a su súbditos para que entregasen los diezmos y donativos más que a aquella iglesia en la que durante todo el año asistían a los rezos, las misas y en las que recibían los demás servicios, [...] todos los Barones Alaveses que eran patronos de iglesias, viendo que éstas estaban reducidas casi a la nada, ya que en la actualidad no recibían los diezmos que les correspondían, pidieron al señor Obispo que de su jurisdicción asignase pueblos a dichas iglesias, de modo que en las mismas pudieran recibir en adelante diezmos eclesiásticos" (Sáenz de Buruaga 1991: 172-173).
}

tesis doctoral defendida en la Universidad del País Vasco UPV/EHU el 15 de enero de 2016, inédita.

Azkarate, A. 1995: "Aportaciones al debate sobre la arquitectura prerrománica peninsular: la iglesia de San Román de Tobillas (Álava)", Archivo Español de Arqueología 68, 189-214.

Azkarate, A. y García Camino, I. 2012: "El espacio circumpirenaico occidental durante los siglos vi al X d. C. según el registro arqueológico: algunos interrogantes", E. Caballero, P. Mateos y C. García de Castros (eds.), Asturias entre visigodos y mozárabes, Madrid, 331-352.

Azkarate, A., García, I. y Solaun, J. L. 2013: "El asentamiento altomedieval de Gasteiz", A. Azkarate y J. L. Solaun (coords.), Arqueología e historia de una ciudad. Los orígenes de Vitoria-Gasteiz, Bilbao, 399-446.

Azkarate, A. y Solaun, J. L. 2013: "El registro arqueológico", A. Azkarate y J. L. Solaun (coords.), Arqueología e historia de una ciudad. Los orígenes de Vitoria-Gasteiz, Bilbao, 75-91.

Azkarate, A. y Solaun, J. L. 2016: "La cerámica altomedieval en el País Vasco (siglos V-X d. C.): producciones, modelos productivos y patrones de consumo", A. Vigil-Escalera y J. A. Quirós (eds.), La cerámica de la Alta Edad Media en el cuadrante noroeste peninsular (siglos $\mathrm{V}$-X). Sistemas de producción, mecanismos de distribución y patrones de consumo, Documentos de Arqueología Medieval 9, Bilbao, 193-228.

Bianchi, G. 1996: "Trasmissione dei saperi tecnici e analisi dei procedimenti costruttivi", Archeologia dell'Architettura 1, 53-64.

Carandini, A. 1997: Historias en la tierra, Barcelona.

Carl, C. 2011: A Bishopric between three kingdoms. Calahorra 1045-1190, Leiden.

Catafau, A. 2007: "Les celleres del Rosselló de mitjan segle XIII a la fi del segle Xv. Permanencies i evolució d'una forma d'estructuració del poblament", V. Farías, R. Martí y A. Catafau (eds.), Les sagreres a la Catalunya medieval, Girona, 205-231.

Coll, J. M., Buxó, J. y Molina, J. A. 2001: "Església Vella de Sant Menna (Sentmenat, Vallès Occidental)", Genera i Monells, M. (coord.), Actes de les Jornades d'Arqueologia i Paleontologia 2001: Comarques de Barcelona 1996-2001, Barcelona, 1130-1136.

Davies, W. 2007: Acts of Giving. Individual, Community, and Church in Tenth-century Christian Spain, Oxford.

De Mañaricua, A. E. 1964: Obispados de Álava, Guipúzcoa y Vizcaya hasta la erección de la diócesis de Vitoria, Victoriensia, Vitoria-Gasteiz, Publicaciones del Seminario de Vitoria 19.

Díaz de Durana, J. R. y Guinot, E. 2010: "La dîme dans l'Espagne médiévale", R. Viader (ed.), La dîme dans l'Europe médiévale et moderne. Actes des XXXes Journées Internationales d'Histoire de l'Abbaye de Flaran, 3 et 4 octobre 2008, Toulouse, 63-88.

Farias, V. 2007: "La proclamacio de la Pau i l'edificacio dels cementiris. Sobre la difusio de les sagreres als bisbat de Barcelona i Girona (segles XI-XIII)", V. Farias, R. Marti y A. Catafau, Les sagreres a la Catalunya medieval, Girona, 13-84.

Fernández Conde, F. J. 1987: La iglesia de Asturias en la Baja Edad Media: estructuras económico-administrativas, Oviedo.

Fernández Conde, F. J. 2000: La religiosidad medieval en España. Alta Edad Media (siglos VII-X), Oviedo.

Fernández de Jauregui, A. 2005: "Casa Consistorial. Iglesia de San Martín (Salvatierra)”, Arkeoikuska 2004, 243-250. 
García Camino, I. y Neira, M. 2007: "Ermita de Santa Lucia de Gerrika", Arkeoikuska 2006, 368-370.

García de Cortázar, J. A. 2008: "La organización socioeclesiológica del espacio en el norte de la Península Ibérica en los siglos viII al XIII", J. A. Sesma y C. Laliena (eds.), La pervivencia del concepto. Nuevas reflexiones sobre la ordenación social del espacio en la Edad Media, Zaragoza, 13-56.

Gurruchaga, I. 1951: "Localización de algunas ciudades várdulas citadas por Mela y Ptolomeo", Boletín del Instituto Americano de Estudios Vascos 7, 222-231.

Larrea, J. J., 2007: “Construir iglesias, construir territorio: las dos fases altomedievales de San Román de Tobillas (Álava)", J. López Quiroga (ed.), Monasteria et Territoria. Elites, edilicia y territorio en el Mediterráneo medieval (siglos $V$-XI), Madrid, 321-336.

Larrea, J. J. 2016: "Las iglesias de los vascones: una problemática antigua y un registro arqueológico nuevo (siglos VI y VII)", J. A. Fernández de Córdoba (coord.), Estudios sobre la Edad Media en el norte de la península ibérica. Jornadas sobre Arqueología Medieval organizadas por APIAA en 2013, 2014 y 2015, Anejos de Nailos 3, Oviedo, 221-248.

Lasagabaster, J. I., Azkarate, A., y De la Fuente, A. 2006: Plan Director de intervención para la restitución de los valores históricos y simbólicos de la Basílica de San Prudencio de Armentia y su entorno, Grupo de Investigación en Arqueología de la Arquitectura de la Universidad del País Vasco UPV/EHU.

Loza, M. y Niso, J. 2012: "Yacimiento de San Martín de Dulantzi", Arkeoikuska 2011, 35-57.

Loza, M. y Niso, J. 2015: "San Martín de Dulantzi”, Arkeoikuska 2014, 21-27.

Loza, M. y Niso, J. 2016: "La basílica tardoantigua de San Martín de Dulantzi (Alegría-Dulantzi, Álava)", Pyrenae 47, 2, 95-129.

Llorente, J. A. 1808: Noticias históricas de las tres provincias vascongadas: Álava, Guipúzcoa y Vizcaya. Parte III. Apéndice o colección diplomática, Madrid.

Martí, R. 2006: "Del fundus a la parrochia. Transformaciones del poblamiento rural en Cataluña durante la transición medieval", Ph. Sénac (ed.), De la Tarraconaise à la Marche Supérieure d'al-Andalus (IV-XI siècle). Les habitats ruraux, Toulouse, 145-166.

Martí, R. 2007: "L'Ensagrerament: Utilitats d'un concepte", V. Farías, R. Martí y A. Catafau (eds.), Les sagreres a la Catalunya medieval, Girona, 85-204.

Portilla, M. 1978: Torres y casas fuertes en Álava, VitoriaGasteiz.

Quirós, J. A. 2012: Arqueología del campesinado medieval. La aldea de Zaballa, Documentos de Arqueología Medieval 3, Bilbao.

Quirós, J. A. 2013: "Silos y sistemas de almacenaje en el País Vasco en la Alta Edad Media", A. Vigil-Escalera, G. Bianchi y J. A. Quiros (eds.), Horrea, barns and silos. Storage and incomes in Early Medieval Europe, Documentos de Arqueología Medieval 5, Bilbao, 171-192.

Reyes, F. 1991: "Arqueología y cultura material de Burgos en la Alta Edad Media", II Jornadas Burgalesas de Historia. Burgos en la Alta Edad Media, Burgos, 77-123.

Rodríguez R. de Lama, I. 1979: Colección diplomática medieval de La Rioja. Tomo III: Documentos (1168-1225), Logroño.

Rodríguez R. de Lama, I. 1989: Colección diplomática medieval de La Rioja. Tomo IV: Documentos del siglo XIII, Logroño.
Roig, J. 2013: "Silos, poblados e iglesias: almacenaje y rentas en época visigoda y altomedieval en Cataluña (siglos VI al XI)", A. Vigil-Escalera, G. Bianchi y J. A. Quiros (eds.), Horrea, barns and silos. Storage and incomes in Early Medieval Europe, Documentos de Arqueología Medieval 5, Bilbao, 145-170.

Sáenz de Buruaga, E. 1991: Historia de Estíbaliz, VitoriaGasteiz.

Sáenz de Haro, T. 2012: Calahorra y su entorno rural (10451295). Expansión demográfica y económica e implantación y transformaciones de las estructuras feudales en una ciudad de la frontera castellano-navarra, tesis doctoral, Universidad de Salamanca, inédita.

Sáenz de Urturi, F. 1985: "Castros de Lastra (Caranca). XI Campaña de excavaciones", Arkeoikuska 1984, 24-26.

Sáenz de Urturi, F. 1986: "Avance al estudio de cerámicas medievales en Álava”, Actas del I Congreso de Arqueología Medieval Española, vol. V, 473-494.

Sáenz de Urturi, F. 1988: "Castros de Lastra (Caranca). XIV Campaña de excavaciones", Arkeoikuska 1987, 24-27.

Sáenz de Urturi, F. 1990: "La Arqueología Histórica (Medieval) en Álava en los últimos 25 años", Munibe (AntropologiaArkeologia) 42, 365-372.

Sáinz Ripa, E. 1994: Sedes episcopales en La Rioja (siglos IVXIII), Diócesis de Calahorra y la Calzada, Logroño.

Sánchez Zufiaurre, L. 2007: Técnicas constructivas medievales. Nuevos documentos arqueológicos para el estudio de la Alta Edad Media en Álava, Vitoria-Gasteiz.

Schiffer, M. B. 1988: “¿Existe una 'premisa de Pompeya' en arqueología?", Boletín de Antropología americana 18, 5-31.

Sharpe, R. 1992: "Churches and communities in early medieval Ireland: towards a pastoral model", J. Blair y R. Sharpe (eds.), Pastoral Care Before the Parish, Leicester, 81-109.

Solaun, J. L. 2005: La cerámica medieval en el País Vasco (ss. VIII-XIII). Sistematización, evolución y distribución de la producción, Vitoria-Gasteiz.

Solaun, J. L. 2013: "La cerámica medieval en Gasteiz (siglos VIII-XII d. C.)", A. Azkarate y J. L. Solaun (coords.), Arqueología e historia de una ciudad. Los orígenes de VitoriaGasteiz, Bilbao, 195-244.

Sopelana I. 2012: "Estudio arqueobotánico del yacimiento de Zaballa (Iruña de oca, Araba-Álava)", J. A. Quirós (dir.), Arqueología del campesinado medieval. La aldea de Zaballa, Documentos de Arqueología Medieval 3, Bilbao, 452-478.

Utrero, M. A. y Moreno, F. J. 2015: "Evergetism among the Bishops of Hispania between the Sixth and the Seventh Centuries: a dialogue between Archaeological and Documentary Sources", Journal of Early Christian Studies 23/1, 97-131. https://doi.org/10.1353/earl.2015.0005

Vigil-Escalera, A. 2013: "Ver el silo medio lleno o medio vacío: la estructura arqueológica en su contexto", A. VigilEscalera, G. Bianchi y J. A. Quiros (eds.), Horrea, barns and silos. Storage and incomes in Early Medieval Europe, Documentos de Arqueología Medieval 5, Bilbao, 127-144.

Villaginés, J. 1988: "El Fenomen parroquial en la societat del Vallès Oriental a l'alta Edat Mitjana (ss. XI i XII)", Acta historica et archaeologica mediaevalia IX, 125-142.

Wood, S. 2006: The Proprietary Church in the Medieval West, Oxford.

Recibido: 22-08-2016

Aceptado: 10-01-2017 